\title{
THEORY OF EVAPOTRANSPIRATION
}

\author{
1. Transpiration and its quantitative description
}

\author{
ANATOLIJ IVANOVIČ BUDAGOVSKYI ${ }^{1 \dagger}$, VILIAM NOVÁK ${ }^{2)}$ \\ ${ }^{1)}$ Institute of Water Problems, Russian Academy of Sciences, Gubkina St. 3, 117971 Moscow, Russian Federation. \\ ${ }^{2)}$ Institute of Hydrology, Slovak Academy of Sciences, Račianska 75, 83102 Bratislava, Slovak Republic, Europe; \\ Mailto:novak@uh.savba.sk
}

Basic information about the evapotranspiration and its components is presented. System of equations describing the transport of water and energy in the soil - plant continuum is analyzed. The system of five differential equations with five unknowns is proposed, describing transport of heat and water vapour within the plant canopy, including exchange processes among the leaves and the atmosphere, vertical transport of the heat, water vapour and the energy balance.

KEY WORDS: Evapotranspiration, Transpiration, Evaporation, Soil Water, Water Balance.

Anatolij Ivanovič Budagovskij, Viliam Novák: TEÓRIA EVAPOTRANSPIRÁCIE: 1. Transpirácia a jej kvantifikácia. J. Hydrol. Hydromech., 59, 2011, 1; 22 lit., 8 obr., 4 tab.

Príspevok obsahuje základné informácie o evapotranspirácii a jej zložkách, výpare a transpirácii. Proces prenosu vody a energie v systéme pôda - porast je opísaný systémom piatich diferenciálnych rovníc kvantifikujúcich prenos vodnej pary a tepla medzi listami a atmosférou, ktoré umožnujú výpočet charakteristík vertikálneho prenosu vody a tepla v poraste a tiež bilanciu energie v tomto systéme.

Klúčové slová: evapotranspirácia, transpirácia, evaporácia, pôdna voda, bilancia vody.

\section{Movement of water from soil to canopy}

Water movement from soil to the canopy leaves, is the most important part of the more general interdisciplinary problem - transpiration process formation - as well as of the heat and water regime of the canopies formation. Formulation of this problem was given by Budagovskij and Lozinskaja (1996).

Biophysical approach to the quantitative description of this process should be based on qualitative results of the plant physiology. It is accepted today, that the fundamental laws of physics and chemistry are base of the plant growth. But the final effect of the above mentioned laws depends on conditions of their applications. It can be considered, that plants during their evolution, depend on climate and local conditions. They were created themselves as kinds of structures, in which general laws of nature were functioning optimally. Those structures are complicated, therefore even qualitative analysis of them is rather difficult. For quantitative analysis, it seems to be reasonable, to analyze the most important laws only.
We start with short description of water transport in the soil - plant system, as it was formulated by the plant physiologists. Those ideas were developed during decades and they can be taken as the classical ones. The later results of research having fragmentary character, will be generally ommited.

Water is transported from soil to plant through the highly developed root system. Information about these systems - elaborated basically by Dettmar, can be found in many monographs (e.g. Maximov, 1958; Peterburskij, 1964; Sabinin, 1955; Waisel et al., 1996). Experiments were performed in wooden boxes of $1 \mathrm{~m}^{3}$ volume, with winter barley canopy. Total length of roots in those boxes was about $600 \mathrm{~km}$, and the total root surface was found to be $225 \mathrm{~m}^{2}$, for the earing ontogenesis phase. To those roots were joined 15 billions of root hairs, of total length of appr. 10 thousand $\mathrm{km}$, and its surface was about $400 \mathrm{~m}^{2}$. Every day, approximately 119 millions of the new root hairs appeared, with total lenght of about $80 \mathrm{~km}$. Leaf area index (LAI) of the winter barley canopy was 4.5 .

Soil water is extracted by plants mainly by root hairs. Typical parameters of the root hairs are given 
by their length $100-1000 \mu \mathrm{m}$, diameter $8-12$ $\mu \mathrm{m}$, and duration of life -1 day. It was found, however, that for fruit and forest trees, the root hairs can live longer (Muromcev, 1969). Plant physiologists deduced, using data of the root hairs length and of their specific surface, that not water is flowing to roots only, but root hairs are approaching soil water too, e.i. roots are hydrotropic, as well as chemotropic.

Now, it seems to be reasonable to discuss the soil water mobility. Two or three days after heavy rain on the soil profile, the soil water content corresponding to a particular soil hydrological constant is usually established. This constant is the minimum water capacity (MWC) for the deep groundwater table level, or hydrological constant field capacity (FC) for groundwater table level close to the soil surface. Soil water content corresponding to those two hydrological constants, is supposed to be upper limit of the soil water content, corresponding to optimum conditions for the plant growth. For higher values of this soil water content, the soil aeration is low, and roots function is limited. Soil is highly conductive for soil water in states containing it close to constants MWC and FC. In such state, water lost by transpiration is partially compensated. Conductivity of soil for water decreases significantly with the decrease of the soil water content, and in such a dry state, it is then reducing the soil water extraction by roots significantly. Under such condition, as it follows from evaluations, root hairs can grow more rapidly, than is the soil water transport velocity to the root hairs.

Soil water is held in soil by cappillary - sorption forces. Intensity of interactions between water and its solid phase, can be characterized by the difference between chemical potential of the clear water with horizontal water table surface, and the chemical potential of water held by cappillary - sorption forces. This difference (with the negative sign) is indicated as the soil water potential, and it can be expressed in pressure units. In this respect in soil physics, it is frequently expressed as the "negative pressure of the soil water". It often implies misunderstandings, even among specialists. Therefore, to simplify the term "soil and plant water potential", it should will be used prefferably the wording "higher" or "lower", according to their absolute values. Of course, water in the soil - plant system, moves from points with lower water potential to those with its higher absolute values.

Cells of root hairs contain solution of high - molecular materials with its osmotic pressure between
$0.1-0.2$, and sometimes $0.3 \mathrm{MPa}$. Soil water potential of the irrigated soil is usually lower in absolute values. Walls of the root - hair cells can be regarded as semipermeable membranes, and therefore in the soil - root system, osmotic pressure is generated which is often assigned by plant physiologists as the root pressure. Due to this phenomenon, water flows through the root cells and through the xylem into the leaves.

Appearance of the liquid water on leaves surfaces can be observed (guttation) due to the root pressure action, when liquid phase change to vapour phase (transpiration), and it cannot be performed at the intensity equal to that of the water transport to the surface. This phenomenon can be observed for net radiation intensity close to zero, high air humidity and relatively high soil water content. Appearance of water from cutted plant stems can be observed at high soil water content too. However, root pressure is not high enough to transport water from the soil to leaves during the meteorological conditions at high net radiation (during the hot days, particularly at noon). Several flexible mechanisms have been formed during the evolution process, which enable transport of water from soil to the whole plant. Basic principles of these mechanism are the following.

In leaves, there are tissues, called parenchym. Structure of this tissues is relatively complex, therefore we can use simplified and popular description, presented by Maximov (1958).

Typical plant cell can be presented as a "bubble" filled up by the cell solution, outer part of which is the cellulose covering. A cover is firm enough to keep its shape, it is elastic and permeable for water. Cell solution with high osmotic potential exerts additional pressure on outer walls of such cell "bubble“. Cell walls, under normal conditions, are under pressure which is called the turgor pressure (usually the word pressure is replaced by word potential). Turgor potential equals to a cell osmotic potential under the static conditions. The difference between both values is called the leaf water potential. In the past, this value was indicated also as the "suction force", which is not correct, but basicaly reflects its function.

In a case, when the cell losses part of its water, it can be uptaken from adjoining cells, having lower water potential than the cell mentioned. This is briefly a way, how the cells are interacting between themselves.

Dense packed epidermal cells are covered on the top by a hydrophobic cuticula. Leaf surface created 
by cuticula is characterized by the low permeability for water vapour.

Leaf mesophyl is composed by parenchym cells, with a free space among them. This space has a surface covered by relatively thin specific cells, creating stomata. They are open during the full hydration of cells, and are continuously becomming closed, according to its (hydration) decrease. There are even other reasons for the stomata activity, but they are of secondary importance, and therefore not mentioned here.

Change of water from liquid to vapour phase, takes place in cappilaries of the cell walls, interfacing the intra-cell space, where the water vapour moves to stomata and further on to the leaf surface, and to the atmosphere. Small part of water vapour is transported to the atmosphere through cuticula. This is called the cuticula transpiration.

In literature, there were reported "energy dependent microchanges of pressure potential of parenchym cells" (Tarcevskij, Zolkevicz (Eds.), 1989), found out by carefull experiments. This phenomenon is not involved in governing theories, but it probably influences the water transport mechanism from soil to plant leaves less significantly. Because of its significance for plant, it can probably play some role also in metabolics exchange between floem and xylem tissues. We can focus our attention to the information published in sixties and at the beginning of seventies (partial list of literature can be found in Tarcevskij, Zolkevicz (Eds.), (1989), declaring, that growth rate decrease is due to the $\mathrm{CO}_{2}$ penetration to the leaf, which is performed because of "overfeeding" of them by the assimilation products. Result of this phenomena is decrease of the metabolic rate and transport of the metabolics to the growth areas and their retention.

Full and reliable description of water transport in this complex system - involving roots and the above ground part of plant - is complicated. Such problems should be solved in the framework of the plant canopy biophysics. This discipline is not ready to solve this problem. Complexity of those phenomena - even if they would be solved - needs to simplify them for the application purposes. Therefore, we can use relatively simple approach, supported by the currently assesed experimental material. Results of calculation, based on the presented approach, should be verified independently.

Analysis of the water transport from the soil to plant, can be started by the equation of the canopy water balance, involving both, the root system, as well as the above ground part of canopy. This equation can be written as

$\mathrm{d} V / \mathrm{d} t=v_{p}-E_{t}$,

where $V$ is the whole plant water content per unit soil surface area, $v_{p}$ - water transport intensity from soil to plant, $E_{t}$ - water vapour transport intensity from plant leaves to the atmosphere (transpiration).

Transpiration $E_{t}$ in this chapter is a result of direct measurement. Formation of it is described in detail here. To evaluate $v_{p}$, it can be developed a relationship, taking into account the following assumptions:

- $v_{p}$ should be proportional to the difference $\psi_{l}-$ $\psi_{r}$, where $\psi_{l}$ - leaf water potential, $\psi_{r}$ - root hair water potential.

- active root hair (root hairs uptaking water) water potential should equal to average value of the soil water potential in the depth $z$.

- root pressure can be neglected, because of its small additional value to the leaf water potential.

With the above mentioned assumptions it can be written:

$v_{p}=K_{p}\left(\psi_{l}(t)-\psi_{r}\right)$.

$K_{p}$ is integral coefficient of the canopy hydraulic conductivity as a whole. Methods of its assessment are described later. It can be shown, that the value of $\psi_{r}$ can be taken as a constant during a day.

Using (1) and (2), it can be written

$\mathrm{d} V / \mathrm{d} t=K_{p}\left(\psi_{l}(t)-\psi_{r}\right)-E_{t}(t)$.

According to the previously stated assumptions, the right side of the Eq. (3) can be known, to calculate $\mathrm{d} V / \mathrm{d} t$. It seems to be more suitable - hovewer to integrate the Eq. (3) according to $t$, starting with $t(0)$, which should equal to the sunrise time. As a result of integration

$V(t)-V(0)=\int_{0}^{t}\left[K_{\mathrm{p}}\left(\psi_{l}(t)-\psi_{r}\right)-E_{t}(t)\right] \mathrm{dt}$.

Using calculated values $V(t)$ and measured $\psi_{l}(t)$, a linear empirical relation between them can be estimated as

$\psi_{l}(t)=\beta_{p}(V(t)-(V(0))$.

Parameter $\beta_{p}$ estimation technics is simple and needs no further description.

Differentiaiting (5) according to $t$ and substituting $\mathrm{d} V / \mathrm{d} t$ to (3), after the folloving simple tranformation, the equation can be derived 
$\mathrm{d} \psi_{l} / \mathrm{d} t+K_{p} \beta_{p}\left[\psi_{l}(t)-\psi_{r}(0)\right]-\beta_{p} E_{t}=0$.

Leaf water potential is of sine function shape during the sunny days - its maximum is usually 30 to 50 minutes after noon (according to the local sun time). For this case, from the Eq. (6), for $\mathrm{d} \psi_{l} / \mathrm{dt}=0$ it can be writen

$$
K_{p}=E_{t} /\left(\psi_{1} \max -\psi_{r}(0)\right)
$$

Because $\psi_{r}(0)=\psi_{s}$, daily course of the soil water content, and the soil water potential as well, are not so distinctive in comparison to the leaf water potential. Therefore, it can be supposed for a day, that $\psi_{r}(0)=\psi_{s}=$ const.
Estimation of $K_{p}$ starts with preliminary evaluation of the maximum $\psi_{l}(t)$, according to the course of $\psi_{l}=f(t)$. Next step is estimation of the $E_{t}=v_{s}$ max, using daily course of the $E_{t}=f(t)$. Then, using $\psi_{l}(t)$ course, the value of $\psi_{l}(0)=\psi_{s}$ can be estimated, corresponding to the time of dawn. Then, value of the $K_{p}$ can be calculated, using Eq. (7). For potentials expressed in $\mathrm{Pa}$ and $E_{t}$ in $\mathrm{mm} \mathrm{h}^{-1}$ parameters $K_{p}$ and $\beta_{p}$ are shown in Tab. 1. They are results of the field measurements. Because of relatively low number of such results, the statistical parameters of the measured values are not shown there, but only the average and limiting values as well.

T a b l e 1. Parameters $K_{p}\left[\mathrm{~mm} \mathrm{~h}^{-1} \mathrm{MPa}^{-1}\right]$ and $\beta_{p}\left[\mathrm{MPa} \mathrm{mm}{ }^{-1}\right]$.

\begin{tabular}{cccccccc}
\hline Crop & $\begin{array}{c}\text { Number of } \\
\text { events }\end{array}$ & $\overline{K_{\mathrm{p}}}$ & $K_{p \max }$ & $K_{p \min }$ & $\overline{\beta_{\mathrm{p}}}$ & $\beta_{p \max }$ & $\beta_{p \text { min }}$ \\
\hline Maize & 7 & 0.37 & 0.57 & 0.13 & 1.44 & 2.40 & 0.76 \\
Wheat & 6 & 0.78 & 0.97 & 0.55 & 1.28 & 2.30 & 0.36 \\
Buckwheat & 2 & 3.87 & 4.55 & 3.08 & 0.16 & 0.18 & 0.13 \\
\hline
\end{tabular}

Coming back to the differential Eq. (6), its solution under condition of $\psi_{l}(0)=\psi_{s}$, can be presented as

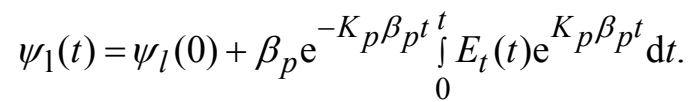

To estimate $\psi_{l}(t)$ using Eq. (8), values of $E_{t}$ and $\psi_{l}(0)$ must be known from the measurements. Suitable methods for the $E_{t}$ estimation are described later. Modification of the "isotonic solution" was used to estimate $\psi_{l}(t)$, (Budagovskij, 1964). Measurements were performed in the three hourly intervals, starting from $1 \mathrm{pm}$, according to the local suntime. Parametres $K_{p}$ and $\beta_{p}$ were estimated from Tab. 1. Calculations were performed in two ways: first one was the estimation, using individual parameters derived for any arbitrary day; in the second case, the average values of parameters for all the time intervals under consideration were taken.

On the graphs of these relationships, their values of the measured and calculated values of $\psi_{l}(t)$, are grouped well around the line of symetry. Correlation coefficient for the first case of calculation was 0.99 , for the second case it was 0.98 . This means, that both relatively simple methods are well suitable for the use. Important is, that dispersion of the parametres $K_{p}$ and $\beta_{p}$ is not critical, for calculation of $\psi_{l}(t)$.

By combination of Eqs. (2) and (8) it can be written
$v_{p}(t)=K_{p} \beta_{p} \mathrm{e}^{-K_{p} \beta_{p} t} \int_{0}^{t} E_{t}(t) \mathrm{e}^{K_{p} \beta_{p} t} \mathrm{~d} t$.

Fig. 1 demonstrates daily course of the measured transpiration values, as well as of the estimated water flow rate values from soil to leaves, using Eq. (9). The area between both courses demonstrates decrease of the water content in a canopy, during the first half of the day, and its rehabilitation during its second half. Replenishment of the canopy water starts soon after sunrise and its restoring begins soon after the noon. It is shown, that often used condition $E_{t}=v_{p}$, is an approximation only.

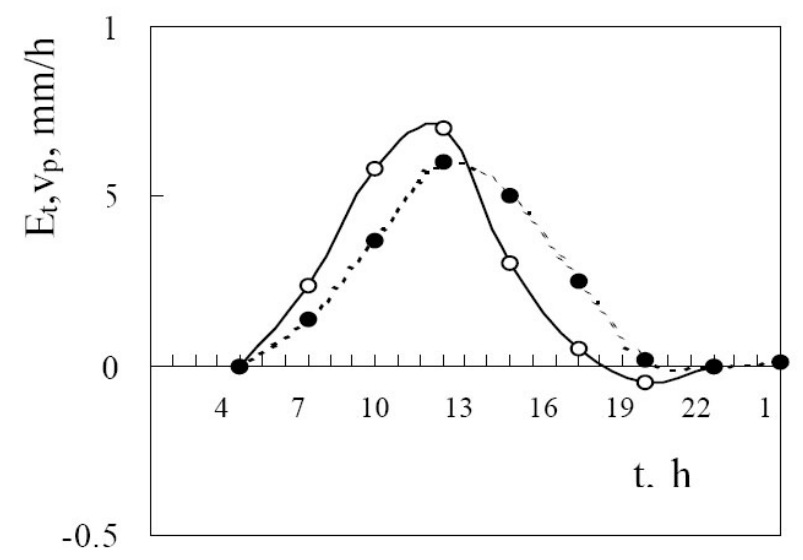

Fig. 1. Transpiration $E_{t}$ daily course (empty circles) and water flow rate to the plant leaves $v_{p}$ (full circles). 
It was demonstrated, that quantitative description of the transpiration presented here is relatively simple, and results of calculation are close to the measured data. The next step is estimation of the water vapour transport from leaves to the atmosphere.

\subsection{Leaf transpiration analysis}

Leaf is a basic transpiring element of a plant. Therefore, it seems to be meaningfull to start transpiration analysis from a single leaf - or detached part of it. Such a part of the leaf can be taken as a flat membrane. In this case, it can be reasonable to start with application of some basic rules of the heat and energy transport theory on the leaf transpiration.

At the very beginning, the equation of energy balance can be written:

$R=L E+P$,

where $R$ - net radiation, $L$ - latent heat of evaporation, $E$ - water vapour flux (term $L E$ is often noted as the latent heat flux), $P$ - sensible heat flux.

Equations for $L E$ and $P$ can be written as:

$$
\begin{aligned}
& L E=\rho L D_{l}\left(q_{l}-q\right) ; \quad D_{l}=\frac{D_{t}}{1+D_{t} / D_{y}}, \\
& P=\rho c_{p} D_{t}\left(T_{l}-T\right),
\end{aligned}
$$

where $\rho$ - air density, $q$ - absolute humidity, a $T-$ air temperature near the leaf, $T_{l}$ - leaf temperature, $q_{l}$ - saturated air humidity in inter- cells leaf space, $c_{p}$ - specific heat capacity at the constant air pressure, $L$ - latent heat of evaporation, $D_{l}$ and $D_{t}-$ coefficients of water and heat transport between the leaf and its environment, respectively, $D_{y}-$ stomata conductivity.

Relationship between $D_{t}$ and environment properties can be developed within the framework of the mass and energy transport theory. The theory is usually using dimensionless numbers of Nusselt $\mathrm{Nu}=D_{t} l / \varepsilon$, and of Reynolds $\operatorname{Re}=u l / v$, Schmidt number $\mathrm{Sc}=v / \varepsilon$ for the mass transport, and Prandtl number $\operatorname{Pr}=v / a_{t}$. For the heat transport, the following interrelation is used

$$
\mathrm{Nu}=0.664 \mathrm{Sc}^{1 / 3} \mathrm{Re}^{0.5},
$$

where $\varepsilon$ - molecular diffusion coefficient of water vapour in the air, $v$ - air kinematic viscosity coefficient, $l$ - length of an element under study in the direction of wind velocity $u$. In such a way, the problem of $D_{t}$ estimation for leaf element can be solved.

Substituting terms $\mathrm{Nu}, \mathrm{Sc}$ and $\mathrm{Re}$ into (13), the resulting equation for $D_{t}$ is

$$
D_{t}=c_{t}(u / l)^{0.5} \text {. }
$$

In this equation $c_{t}$ contains terms $\varepsilon, v$ and the constant 0.664 . Formula (14) is valid for the forced convection, due to wind blowing around the leaf. Free convection can be developed, when wind velocity is close to zero, due to air density differences at the leaf surface and nearby. Mixed convection comes into action, under small Reynolds numbers, which is not well understood. Mixed regime of convection will not be analysed later. Therefore, in our case it is quite acceptable to use the simplest correction rewriting (14) into

$D_{t}=c_{t}(\xi+u / l)^{0.5}$.

According to preliminary evaluation, $\xi$ values can be found within the interval $0.2-0.3 \mathrm{~m} \mathrm{~s}^{-1}$.

To complete the system of equations described, it needs a complementary relationship between $q_{l}$ and $T_{l}$. Dynamic meteorology is using usually the Magnus formula

$q_{l}=q_{m}(0) \exp \left(\frac{17.1 T}{235+T}\right)$

where $q_{l}$ - saturated air humidity in intercellular space of leaf, $q_{m}(0)$ - saturated air humidity for $T=$ $=0{ }^{\circ} \mathrm{C}$.

Substituting (15) into (11), follows then the equation for $L E$, in which the saturated air humidity $q_{l}\left(T_{l}\right)$ is not more involved.

$$
L E=\rho L \frac{D_{t}}{1+D_{t} / D_{y}}\left[q_{m}(0) \exp \left(\frac{17.1 T_{l}}{235+T_{l}}\right)-q\right] \text {. }
$$

By substitution (16) and (12) into (10), it follows the Eq. (17)

$$
\begin{aligned}
& R=\rho L \frac{D_{t}}{1+D_{t} / D_{y}}\left[q_{m}(0) \exp \left(\frac{17.1 T_{l}}{235+T_{l}}\right)-q\right]+ \\
& +\rho c_{d} D_{t}\left(T_{l}-T\right)
\end{aligned}
$$

Transcendent Eq. (17) can be solved by iteration. Value of $T_{l}$ is evaluated, using (15), and $q_{l}$ is estimated. $L E$ and $P$ can be estimated by (11) and (12). 
The Eq. (17), together with the other relationships described above, can be used to estimate coefficients $D_{t}$ and $D_{y}$. Measuring $L E$ independently, evaluation is relatively easy and does not need specific comment. To analyze the transpiration process, relatively simple equation is needed. This equation can be developed, by using the Magnus equation in a form of exponential series, and by taking into account its first two terms. After some rearrangement, these two terms can be taken as

$q=q_{m}+\phi^{\prime}\left(T_{l}-T\right) ; \quad \phi^{\prime}=\frac{\mathrm{d} q_{m}}{\mathrm{~d} T}$,

where $q_{m}$ - saturated air humidity, $T$ - temperature od the air around the leaf.

By the following substitution of (18) into (11), and by expressing $\left(T_{l}-T\right)$ according to (12), and after rearrangements, the following equations are developed

$$
\begin{aligned}
& L E=\frac{1}{1+b_{1} p_{l}}\left(L \rho b_{1} D_{t} d+b_{2} R\right) \\
& b_{1}=1 /\left(1+\frac{L}{c_{p}} \phi^{\prime}\right) ; \quad b_{2}=1-b_{1} ; p_{l}=D_{t} / D_{y} .
\end{aligned}
$$

Errors, introduced into Eq. (19), due to development of Magnus equation into the exponential series, were evaluated by Lozinskaja (1981). Results of errors evaluation were presented as a comparison of ratios $L E / R$, in which $L E$ was evaluated by (19), (11) and (17). On the graph, values $L E / R$ of the interval 0.4-1.6 can be seen, determined by the accurate and by the approximate methods. Points lower than $L E / R=1.3$, can be approximated by the line of symetry. For values $L E / R>1.3$, the points are continuosly declining of it, at $L E=1.5$ the difference is about $3 \%$. Value $L E / R=1.3$ can be reached even in the field conditions in particular cases only. Values $L E / R$, higher than 1.3 , can be observed during the evening and the night time only, when transpiration ceased and condensation (dew formation) starts. From it follows, that the Eq. (19), is fully acceptable approximation, which in the field fully corresponds to the reality.

As a base of approximative and accurate description of the transpiration process, there are two basic equations: the energy balance equation and the transport equations for water vapour and heat. The state of art, does not allow to change this approach. It should be noted, that the first modern approach using the above mentioned equations, was made in
1948 by Penman (1948). At that time, this approach was formulated in a simple way and its weak points can be revealed by a carefull analysis only. The outstanding studies on the evapotranspiration process were performed using this approach. Extension of the results achieved by such approach, can be made by experimental analysis of the evapotranspiration process. Here, our analysis will be limited to the extent of experiments, done by the Institute of Water Problems, Russian Academy of Sciences, Moscow (IVP RAS).

The basic experiments were performed using small aerodynamic tunnel. Cross-section of it was $0.22 \times 0.22 \mathrm{~m}$, length $-1.2 \mathrm{~m}$. In the intake part of the wind tunnel, the aerodynamic screen was located to homogenize the air flow velocity in it. At the distance of $20 \mathrm{~cm}$ from the exhaust end, the highly sensitive anemometer was located, to measure the air flow rate. Intake part of the tunnel was equipped with the ventilator, allowing to keep the air velocity at the range of $0.2-3.2 \mathrm{~m} \mathrm{~s}^{-1}$. Analytical scale with electronic registration was established above the tunnel, allowing to record weight changes of the leaf in the tunnel, up to $10^{-4} \mathrm{~g}$. Wind tunnel body was made of plexiglass. Long-wave radiation coming from the lamp with the output of $400 \mathrm{~W}$ was eliminated by the screen.

The scale was connected to the leaf (or to its part) in the tunnel through a tiny opening in the tunnel wall. This equipment was designed in a way not to disturbe neither the scale function, nor that of the tunnel. Short-wave radiation was measured by pyranometer, before and after the experiment, assuming stable conditions inside of the tunnel. Long wave radiation was evaluated, using difference between the leaf and the air temperature. Air humidity was measured by the aspiration psychrometer as well, as the air temperature. In such a way, all the necessary information was acquired in course of the experiments.

The described apparatus was realtively simple and lightweight, to be established in the field conditions, nearby fields under study.

The first aim of this experimental work was to describe the relationship between leaf transpiration and its water content $v_{l}$, in full range of their realistic values, starting with saturation water content of the leaf, up to its wilting point.

To reach full saturation of the leaves, plants were extracted from the soil in the evening. Stems were dipped down into water, in which plants were preserved until the next day. During the day they were 
covered and periodically sprinkled with water, thus simulating rain. Leaves or their parts were used in the equipment described above. Duration of the experiment was usually 30-40 minutes. During it, mass change of the leaf (or of its part) was recorded and then recalculated to water content of the unit leaf area, as it changed in time $v_{l}=f(t)$. Differentiating it numerically, according to $v_{l}$ and $t$, transpiration of the leaf surface area was calculated $E_{l}=$ $\mathrm{d} v_{l} / \mathrm{d} t=f(t)$. Assigning leaf water content to the given time, relationship between the transpiration and the leaf water content $E_{l}=f\left(v_{l}\right)$ was estimated. All these relationships seem to be similar.

To generalize them, it is necessary to focus on horizontal section of the relationship $E_{l}=f\left(v_{l}\right)$, and on change of its slope when approaching the low leaf water contents.

Change of the relationship $E_{l}=f\left(v_{l}\right)$ slope, behaves in a narrow range of the leaf water contents $v_{l}$. Therefore, the leaf water content corresponding to this change can be taken as a characteristic. As it will be shown, its meaning is crucial and can be noted as $v_{k r}$. Even continuity of the slope change from the first sloped curve to the second one, is experimentally supported well in the range of the leaf water contents $v_{l}$, and error of measurements $\delta E_{l}$, due to approximation of the $E_{l}=f\left(v_{l}\right)$ relationship, is very small too. The second characteristic point on the horizontal coordinate axis can be estimated, noted as $v_{k t}$. For $v_{l}<v_{k t}$, the leaf stomata are probably fully closed, and the cuticular transpiration is taking place only. Now it is clear, how to construct generalized relationship $E_{l}=f\left(v_{l}\right)$. It can be used the ratio $E_{l} / E_{l 0}=\Phi_{l}$, in which $E_{l 0}$ - transpiration at optimum leaf water content, corresponding to the horizontal section of the relationship $E_{l}=$ $=f\left(v_{l}\right)$. On horizontal axis, the dimensionless leaf water content $v_{l}^{*}=\left(v_{k r}-v_{l}\right) /\left(v_{k r}-v_{k t}\right)$ is interpreted. Leaf water content $v_{l}$ is related closely enough to the leaf water potential $\psi_{l}$, which can be taken here as linear. Therefore, instead $v_{l}{ }^{*}$ dimen- sionless leaf water potential $\psi_{l}{ }^{*}$ can be used in the form $\left(\psi_{l}-\psi_{k r}\right) /\left(\psi_{k t}-\psi_{k r}\right)$. Subscripts " $k r^{\prime \prime}$ and "kt" for $\psi$ have the same meaning as for $v$. Note, that $\psi_{l}^{*}=-v_{l}^{*}$. Relationship $\Phi_{l}=f\left(\psi_{l}^{*}\right)$ is presented in Fig. 2.

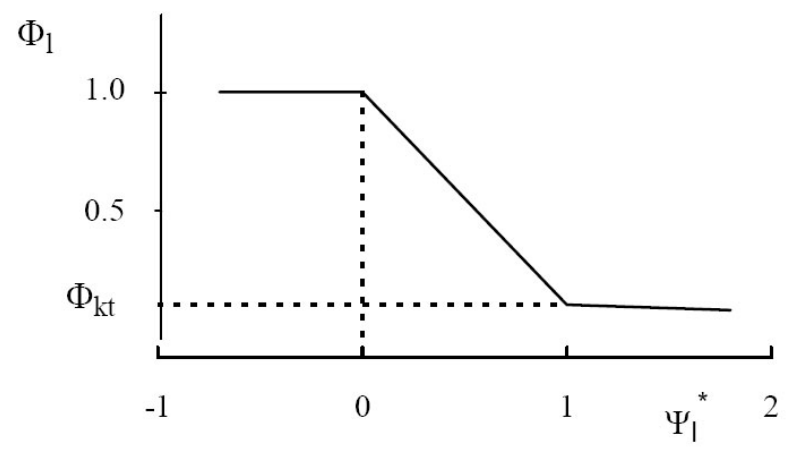

Fig. 2. Scheme of the actual and potential transpiration ratio $\Phi_{l}$, depending upon dimensionless leaf water potential $\Psi_{l}^{*}$.

Relationship $\Phi_{l}=f\left(\psi_{l}{ }^{*}\right)$ is accurate enough for purposes of this analysis. But values of parameters like $v_{k r}, v_{k t}$, and $\psi_{k r}, \psi_{k t}$ are changing in wide ranges as it is typical for biostructures, particulary for leaves. Tab. 2 contains data illustrating these findings.

Relationships in Fig. 2, can be expressed by the following analytical equation, using the dimensionless water content $v^{*}{ }_{l}$ and the leaf water potential $\psi_{l}^{*}$.

$$
\Phi_{l^{*}}= \begin{cases}1 & \text { for } \psi^{*}{ }_{l} \leq 0 \\ 1-\left(1-\Phi_{k t}\right) \psi_{l^{*}} & \text { for } 1 \geq \psi^{*}{ }_{l} \geq 0 \\ \Phi_{k t}=\left(\psi_{l}{ }^{*}-1\right) \eta & \text { for } \psi^{*}{ }_{l}>1\end{cases}
$$

$\mathrm{T}$ a b l e 2. Characteristics of the leaf water regime. Mean values are in numerator, coefficients of variation are in denominator.

\begin{tabular}{|c|c|c|c|c|c|}
\hline Plant type & $\begin{array}{l}\text { Number of ex- } \\
\text { periments }\end{array}$ & $v_{k r}[\mathrm{~mm}]$ & $v_{k t}[\mathrm{~mm}]$ & $\overline{\Phi_{k t}}$ & $\eta$ \\
\hline \multirow[t]{2}{*}{ Corn } & 57 & 0.12 & 0.10 & 0.17 & 0.14 \\
\hline & & $\overline{0.10}$ & $\overline{0.12}$ & $\overline{0.36}$ & $\overline{0.38}$ \\
\hline \multirow[t]{2}{*}{ Wheat } & 20 & 0.09 & 0.06 & 0.21 & 0.16 \\
\hline & & $\overline{0.12}$ & $\overline{0.24}$ & $\overline{0.26}$ & 0.34 \\
\hline \multirow[t]{2}{*}{ Sunflower } & 20 & 0.16 & 0.12 & 0.18 & 0.18 \\
\hline & & $\overline{0.12}$ & $\overline{0.24}$ & $\overline{0.29}$ & $\overline{0.36}$ \\
\hline
\end{tabular}


Study of the $D_{t} / D_{y}$ ratio, is the second important problem which can be solved using the described wind tunnel. It is necessary to solve this second problem experimentally, because value of the $D_{y}$ can be estimated even theoretically, but based on abstraction of the molecular transport mechanism. But, the molecular diffusion coefficient of water vapour in the air is approximately constant with weak relation to the air temperature. Therefore, it seems to be reasonable to expect, that the ratio $p_{l}=$ $=D_{t} / D_{y}$ depends upon the air velocity. If it is so, the leaf transpiration as described by the Eq. (19), should decrease with the wind velocity increasing, especially for net radiation high values. Even in some publications, e.g. (Bichele, Moldau, Ross, 1980), and others, categoric conclusions about decreasing of transpiration with the wind velocity increasing, could be found. Experimentally estimated facts are in contrary to those opinions. Therefore, it is necessary to perform experiments confirming or denying those conclusions. And of course, it is also necessary to find out reasons of those erroneous opinions.

To perform such experiments, it is necessary to use leaf water contents interval in which transpiration is of the constant rate, when the outer conditions are stable. It seems, that water imbibition by the leaf section can be succesfully used. It was also shown, that after at about one hour of transpiration, its ratio is decreasing. The reason of it is probably the assimilates concentration in the leaf. Usually, they are moving in phloem, from which they cannot penetrate to water.

Plants with leaves located close to the soil surface should be used in such experiments. Those plants can be extracted from the soil, together with part of their roots together with the soil. Then, transport of assimilants to the roots and to the leaves will be preserved, because of the low radiation level in the experimental device.

Extracted part of roots and soil was irrigated, then located into small plastic container. This part, together with the leaf, was connected to the analytical scale, using the above described arrangement. Nineteen experiments were performed with leaves of plantain, sorrel, maize and wheat (first fully developed leaf from the beginning of vegetation). 5 to 7 measurements were conducted in every experiment, necessary for evaluation of $D_{y}$. Later, the graph $D_{y}=f\left(u^{1 / 2}\right)$ was derived. To understand the process better, closer to the leaf a segment of the wet blotting paper was located, to estimate the $D_{t}$.
Results of these measurements were drawn, to express the relationship $D_{t}=f\left(u^{1 / 2}\right)$. Because there were differences between the fixed wind velocities for experiments with the leaves, and with the paper (wet body), $D_{t}=f\left(u^{1 / 2}\right)$ were used to estimate $D_{\mathrm{t}}$ values, corresponding to those wind velocities at which $D_{y}$ were measured.

Evaluation of the experiments has shown, that the ratio $D_{t} / D_{y}$ was constant but it changed at repeated experiments with the same plant. Even more, it changed for different plants and different stages of their development. The reason is probably resulting from the natural variability of their biological parameters. Newertheless, for any leaf the value of this difference was the same, do not depending on the air velocity around the leaf. This is illustrated in Fig. 3, where on the vertical axis are values of $D_{y}$, and on the horizontal one are those of the $D_{t} C$, where $C$ is the proportionality coefficient.

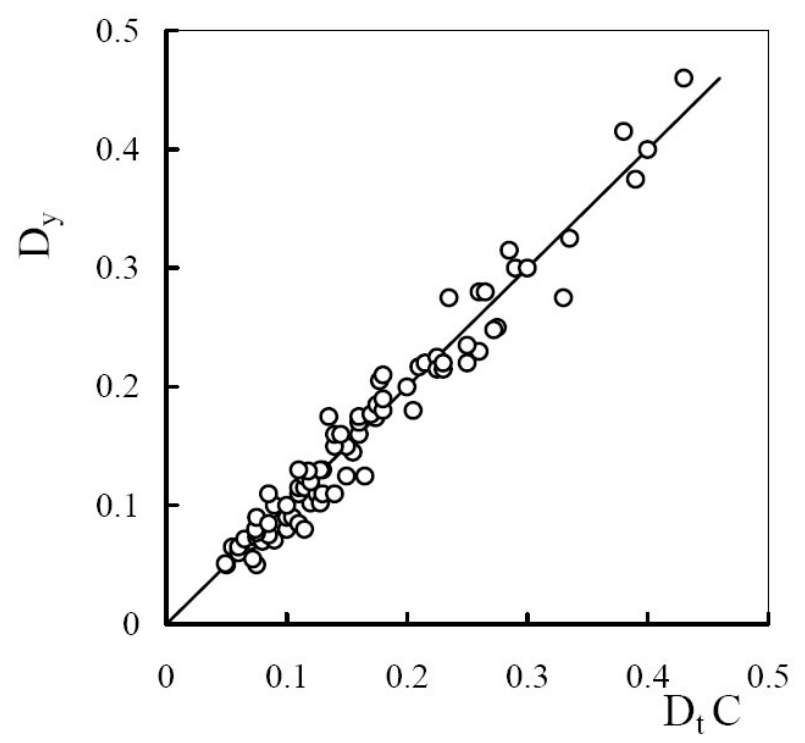

Fig. 3. Relationship between coefficient of stomatal conductivity $D_{y}$ and the heat and water vapour transport coefficient, between leaf and the atmosphere $D_{t} C$.

By this way it was established, that the ratio $D_{t} / D_{y}$ does not depend on the wind velocity. Qualitative type of explanation can be given only until now. Pressure pulsations of the turbulent flow and of the air around the leaf are generated. Ortogonal component of the flow velocity penetrates through thin air boundary layer. Probably, with the wind velocity increase at identical conditions, stomata conductivity can increase too, leading to the transpiration increase as well. 
It is interesting, that Morozov (1938) raised the hypothesis, acoording to which the ortogonal pressure pulsation component of the surface air layer leads to the increase of the atmospheric upper layer diffusion coefficient, which is significantly higher, than that of the molecullar diffusion. Therefore, the above mentioned independence of the ratio $D_{t} / D_{y}$ upon the wind velocity, can be taken as a generalisation of the Morozov hypothesis, for case of the plant leaves stomatal conductivity.

The influence of function $b_{1}$ (depending on the air temperature) upon the term $b_{1} D_{t} / D_{y}$ is the third problem which can be solved, using experimental equipment described above. For this purposes equipment should be modified as to establish the equal air temperatures outside as well as in inside of the wind tunnel. This appeared to be a fairly difficult problem. Therefore, results of the field measurements with transpiration rates and all necessary meteorological characteristics were used. This problem will be discussed later, here are presented some results only. It was estimated, that the ratio $b_{1} D_{t} / D_{y}$ is nearly constant, for the broad range of the function $b_{1}$ values between 0.15 and 0.34 , and of the air temperatures between $38^{\circ} \mathrm{C}$ and 17 ${ }^{\circ} \mathrm{C}$, at the relatively high soil water content values. That means, the term $1+b_{1} p_{l}$ in Eq. (19), containing $b_{1}$, which is a function of the air temperature and wind velocity, depends on $D_{y}$ only. In such a way, simple answer of question related to the influence of stomata conductivity upon the leaf transpiration was estimated.

This result is basic for the transpiration process quantitaive description. It seems to be reasonable to analyze briefly state of the art of this problem.

Bichele, Moldau, Ross (1980), presented state of the art of the stomata resistance values $r_{\mathrm{s}}\left(r_{\mathrm{s}}=1 / D_{y}\right)$ evaluation. Empirical relations between the $r_{\mathrm{s}}$ and the photosyntetically active radiation (PAR), leaf water potential, leaf temperature, and the $\mathrm{CO}_{2}$ concentration, were evaluated in the intercellular leaf area. Influence of the air water vapour pressure gradient, between the intercellular and around the leaf area upon $r_{s}$ was also taken into account.

Estimation of the PAR influence upon $r_{\mathrm{s}}$, can be accepted in principle. But its importance is limited to the early morning and to the late evening periods, when condensation starts according to the actual meteorological conditions. For the last case, the value of $r_{\mathrm{s}}$ does not influence the condensation. Therefore, this problem is not considered here.
Family of formulae was presented, expressing relationship between $r_{\mathrm{s}}$ and the leaf water potential $\psi_{l}$, containing not less than three empirical parameters. In this chapter, formula for $D_{y}$ estimation is presented, (better for $\Phi_{l}$ estimation, which depends upon the $D_{y}$ ), as it follows from the Eq. (21). It contains three parameters too, but they have full physical meaning $-\psi_{k r}, \psi_{k t}$ and $\Phi_{k t}$.

Another family of formulae describing relation between $r_{\mathrm{s}}$ and the air temperature, gives quite different results. Any of them contains at least three empirical parameters too. Conclusions derived from the analysis of this type of formulae, disagree with the conclusions from the term $b_{1} p_{l}$ analysis, estimated from a large number of the field measurement results.

Relationship between $r_{s}$ and concentration of the $\mathrm{CO}_{2}$, is based upon the measurements misinterpretation. Extensive scale research of Kursanov (1976) has shown, that inapropriate plant water regime lead to assimilates accumulation in leaves, and in the $\mathrm{CO}_{2}$ concentration increase, respectively. In this case, this formal relationship is not properly interpreted in the plant physiology.

Similarly, the same can be told about the influence of water vapour pressure gradient upon the $r_{s}$. In this case, probably leaves were kept at the constant temperature, and natural energy balance of the leaf was changed. This resulted in all the nonnatural changes.

To discuss influence of the wind velocity upon $r_{\mathrm{s}} / r_{\mathrm{a}}$, where $r_{\mathrm{a}}=1 / D_{t}$, this problem was supposed to be of a small importance, and has not been studied.

\subsection{Equations of the heat and water transport in the canopy and their solution}

A canopy can be taken as an active layer, in which the heat and water are transported in its radiation and convection modes. This process is complex, therefore even its qualitative description is complicated. Nevertheless, a short and schematic description of the process is presented here.

Basic source of energy for transpiration is the solar radiation, in direct and/or transformed form. The main its components are the direct solar radiation $(S *)$, and the Sun's diffusion radiation $-(s *)$. The term $S_{*}+s_{*}$ is used to indicate the total short-wave radiation. The major part of it is absorbed by the soil surface and by the plant canopy. Its second part forms the so called reflected radiation. Ratio of the reflected short-wave radiation to its total, is denoted 
as albedo $(A *)$. The value $A *\left(S_{*}+S_{*}\right)$ is often noted as the short-wave radiation balance

$B_{k}=A_{*}\left(S_{*}+s_{*}\right)$.

Any body on the Earth, also the soil and the plant canopy, is radiating in the long-wave range. Its value can be estimated using the Stefan - Boltzmann formula

$I_{l}=\sigma * a * T^{4}$,

where $I_{l}$ - long-wave radiation of the body, $T$ - its absolute temperature , $\sigma_{*}$ - Stefan - Boltzmann constant, $a_{*}$ - radiation coefficient, its value for black body is unity. It is often noted as the "coefficient of grey", by which it is stressing the difference between radiation of the particular body and the black one. Atmosphere, better its gaseous components, are radiating too. It is predominantly the water vapour and $\mathrm{CO}_{2}$. Other gases have minor influence upon the radiation. This term, sometimes indicated as radiation of the atmosphere, can be noted as $I_{a}$.

Effective radiation $I_{e}$ is the sum of $I_{l}$ and $I_{a}$. It is accepted, that radiation fluxes directed downward are used to be indicated as positive, upward fluxes are the negative ones. The effective radiation, which is the long-wave radiation balance, can be expressed as

$I_{e}=I_{a}-I_{l}$.

The algebraic sum of all radiation fluxes is used to be indicated as the net radiation $R$.

$R=\left(1-A_{*}\right)\left(S_{*}+S_{*}\right)+I_{a}-I_{e}$.

Now, there is a variety of instruments, suitable to measure the long-wave, as well as the short-wave radiation fluxes. Empirical formulae for calculation of the both types of these fluxes, need standard meteorological parameters only. Limitation of those formulae is, that they are suitable for bare soils and for canopy surfaces only. In a canopy, complex radiation fluxes are taking place, playing decissive role in the transpiration process formation. This problem is attracting a considerable attention of researchers, but by now we are far from the acceptable solution toit. The plant canopy radiation regime is very well presented in the monograph by Ross (1975), which was published already many years ago.

Results presented in this monograph (Ross, 1975), do not contain the information necessary to analyze transpiration process in the full scale.
Therefore, the net radiation will be used as a basic term in the transpiration analysis.

Part of radiation flux approaching the plant canopy surface, reaches the soil surface in proportion given by the plant canopy properties. Radiation flux absorbed by the phytomass elements, is transformed to convective fluxes of the latent $(L E)$ and the sensible $(P)$ heat among the leaves and the air. Transport of the heat and of the water vapour between air in the canopy and the adjacent air layer, is taking part. This is a qualitative picture of the heat and water vapour fluxes in and around the plant canopy, which will be used also to describe the transpiration process quantitatively.

Plant canopy is not a real continuum, but the discrete body. All its characteristics used for its description, are supposed to be averaged in the horizontal plane $x y$, for any co-ordinate $z$ from the soil surface.

To describe heat and water transport in the leafair space, the following equations can be used

$\frac{d P}{d z}=\rho c_{p} d \omega / d z D_{t}(z)\left(T_{l}(z)-T(z)\right)$,

$L \frac{d E}{d z}=\rho L d \omega / d z D_{l}(z)\left(q_{l}(z)-q(z)\right)$,

$D_{l}=D_{t} /\left(1+p_{l}\right) ; p_{l}=D_{t} / D_{y}$.

where $z$-vertical co-ordinate, with its zero value starting from the soil surface upward.

To describe latent and sensible heat fluxes directed vertically from the phytomass surface (mainly leaves) to the interleaves space, formally the same equations are used as those describing transport in the air boundary layer:

$L E=-\frac{\rho L k}{h} \mathrm{~d} q / \mathrm{d} z$,

$P=-\frac{\rho e_{p} k}{h} \mathrm{~d} T / \mathrm{d} z$,

where $k$ - coefficient of the turbulent transport, $h-$ height of the plant canopy.

To the Eqs. (27)-(30) should be added the above mentioned Magnus formula and the energy balance equation, which can be presented as

$\mathrm{d} R / \mathrm{d} z=L \mathrm{~d} E / \mathrm{d} z+\mathrm{d} P / \mathrm{d} z$.

In such a way, system of the six independent equations contains with the six unknowns $-q, q_{l}, T, T_{l}$, $L E$ and $P$, is used. In principle it can be solved. 
But, the above mentioned system contains two transport functions $D_{t}(z), k(z)$, which can be estimated using experimental data only. For $k(z)$, analytical relationships $k=k(z)$ were developed, involving some non-acceptable assumptions. These are too complicated and cannot be used for analytical solution of the equation system presented. The most important characteristic is the net radiation $R$, which is changing with the height too. Generalized quantitative description of the relationship between $R$ and height above the soil surface is not available. However, it can be evaluated using results of the field measurements. The above mentioned three relationships yield much better results, if instead of independent variable $z$, the leaf area index $\omega$ is used. Use of the dimensionless ratio $x=\omega / \omega_{0}$, where $\omega_{0}$ is $\omega$ value at the plant canopy surface, seems to be suitable.

Therefore, substituting variable $z$ for $x$, and transforming system of equations, functions $R=R(x), D_{t}$ $=D_{t}(x)$ and $k=k(x)$ can be expressed by the exponential functions, used in the next sections:

$$
\begin{aligned}
& \frac{\mathrm{d} P}{\mathrm{~d} x}=\rho c_{p} \omega D_{t}(x)\left(T_{l}-T(x)\right), \\
& L \frac{\mathrm{d} E}{\mathrm{~d} x}=\rho L \omega D_{l}(x)\left(q_{l}-q(x)\right), \\
& P=-\frac{\rho c_{p} \eta k}{h} \frac{\mathrm{d} T}{\mathrm{~d} x}, \\
& L E=-\frac{\rho L \eta k}{h} \frac{\mathrm{d} q}{\mathrm{~d} x} .
\end{aligned}
$$

Here $\eta=\mathrm{d} x / \mathrm{d} y, y=z / h$, where $h$ - height of the plant canopy above the soil surface. It can be seen, that $\eta$ equals to ratio of the normalised leaf area index and the normalised height. Subscript " $s$ " indicates the soil surface, i.e. $x=0$, subscript " 0 " - is related to the plant canopy surface $(x=1)$, subscript "2" - to some fixed height above it, which is usually conveniently taken $2 \mathrm{~m}$, height of the standard meteorological observations. Derivatives according to $x$ are indicated by superscript "comma" ('). Empirical relationships for $R(x), D_{t}(x)$ and $k(x)$ can be expressed as:

$$
\begin{aligned}
& R(x)=R_{0} \mathrm{e}^{n \omega(x-1)} \\
& D_{t}(x)=D_{t 0} \mathrm{e}^{m_{t} \omega(x-1)} \\
& k(x)=k_{0} \mathrm{e}^{m_{k} \omega(x-1)} .
\end{aligned}
$$

To make future transformations more comfortable, let us integrate Eq. (31), taking into consideration changes of values $x$ from $x=0$ to $x$, where for $x$ $=0$ (soil surface) is $R(0)=L E(0)+P(0)+B$, where $B$ - soil heat flux.

After some rearrangements

$R(x)=L E(x)+P(x)+B$.

The next rearrangement is suitable to start with Eq. (33), expressing $q_{l}$ by series limited into its two first terms. Then to add and take from the left side of the equation $q_{0}$, (in a case, when meteorological conditions are to be used on the plant canopy surface), or $q_{2}$, (for the fixed height $z_{2}$ ). For that case, we limit ourselves on the first case. It should be noted, that difference between saturated water vapour humidity at $x=1$, and that at the same height $q_{0}$, equals to the air saturation deficit. Resulting equation is

$$
L E^{\prime}=\frac{\rho L \omega D_{t}(x)}{1+b_{1} p_{l}}\left[d-\left(q(x)-q_{0}\right)+\phi^{\prime}\left(T_{l}-T_{0}\right)\right] .
$$

Omitting description of this simple rearrangements, some basic further steps can be mentioned briefly. At first, there is $T(x)$ added and taken to right side of the Eq. (38), subtracting the difference $T_{l}-T(x)$ according to (32), and then Eq. (31) will be applied.

$$
\begin{aligned}
& L E^{\prime}=\frac{1}{1+b_{1} p_{l}}\left[\rho L \omega D_{t}(x) d-\rho L \omega D_{t}(x)\left(q(x)-q_{0}\right)+R^{\prime}+\frac{n D_{t}(x)}{k_{0}} \int_{0}^{x} \frac{(R(x)-B)}{k^{*}(x)}\right] \\
& k^{*}(x)=k(x) / k_{0} .
\end{aligned}
$$

Partial differential equations were developed, using two approaches. The first of them was published already and it will be presented briefly here. The second approach is presented for the first time and therefore it will be given in details. 
Using first approach, the equation for $q(x)$ will be developed. Differentiating Eq. (35), then evaluating $L E$ from (35), and the variable $U(x)=$ $=q(x)-q_{0}$ will be used instead the $q(x)$. After some rearrangements we obtain the linear partial differential equation of the second order for $U$ :

$$
\begin{aligned}
& U^{\prime \prime}+m_{k} \omega U^{\prime}+\frac{1}{1+b_{1} p_{l}} \frac{L \rho \omega_{0} D_{t}(x) U}{k(x)}= \\
& =\frac{1}{1+b_{1} p_{l}} k(x)\left[n \omega_{0} R(x)+\frac{D_{l}(x)}{k_{0}}\left[R_{0}\left(\mathrm{e}^{n-m_{k} \omega(x-1)}-1\right)-B\left(\mathrm{e}^{-m_{k} \omega(x-1)}-1\right)\right]\right] .
\end{aligned}
$$

Boundary conditions for solution of the Eq. (40) are: for $x=1 U=0$; for $x=0 U=U_{s}$.

It can be seen, that the coefficient at $U$ is not constant, because $n \neq m_{k}$, and therefore, the equation can be solved numerically. Neglecting the relation between $x$ and the coefficient, solution of the equation can be performed without difficulties, even if its form seems to be complicated. To present solution in a simple way, it can be written, using $\Phi_{1}, \Phi_{2}, \Phi_{3}$ functions for terms standing at $d_{0}, R$ and $B$. Those functions contain even meteorological quasi constant, like $L, \rho, c_{p}$, and other characteristics, which can be taken as constants. Then,

$U(x)=\Phi_{1}(x) d_{0}+\Phi_{2}(x) R_{0}-\Phi_{3}(B)$.

Differentiating the solution of the equation according to $x$ and to multiply it by $\rho L k(x)$,

$$
L E(x)=\left(1 /\left(1+b_{1} p_{1}\right)\right)\left[\Phi_{1}(x) d_{0}+\Phi_{2}(x) R_{0}-\Phi_{3}(x) B\right]
$$

Simplifications were used to solve Eqs. (41), (42). To confirm its acceptability, it is necessary to compare values of $U(x)$ and $L E(x)$, calculated according to above mentioned solution with those measured in the field.

Results of those estimations are presented on Fig. 4. The comparison was performed in two ways. In the first case, parameters $n, m_{t}$ and $m_{k}$, were used, for the situation in which values $q(x)$ and $L E(x)$ were estimated. For the second case, averaged values of them were used. Coefficients of correlation for both cases were estimated, and the necessary errors of measurements were taken into account. They are evaluated relatively high, their average value is 0.985 . Evaluation performed indicates development and solution of equations as fully acceptable. Functions $\Phi_{i}$ are expressed in a complicated form and contain expression $1 /\left(1+b_{1} p_{l}\right)$, which complicated analysis of the re- sulting solution. Therefore, finding of other approaches becomes actual, to find new form of the analysed problem solution.

In the next part of this presentation, some partial results of Monin and Obukhov $(1953,1954)$ will be used, based on similarity concept of turbulent regime of the temperature stratified atmosphere, accepted world-wide. Relations between vertical profiles of air temperature and air humidity can be taken as linear. As a result of this, the well known Bowen ratio

$$
\mathrm{Bo}=P / L E=c_{p} \mathrm{~d} T / L \mathrm{~d} q
$$

will be linear with maximum at the soil surface adjacent layer. The profile

$$
\theta(x)=q(x)+\frac{{ }^{c} p}{L} T(x)
$$

is suitable for use in this case, and then to write relationship

$$
L E /(R-B)=\mathrm{d} q(x) / \mathrm{d} \theta(x) .
$$

Analogous relation can be written even for

$\frac{P}{R-B}=c_{p} \mathrm{~d} T / \mathrm{d} \theta$.

The sum of those two relations equals to unity. These relationships are constant along elevation in boundary layer of the atmosphere too. Therefore, the question arises, whether those relations can be generalised even for the homogeneous plant canopy. Answer can be obtained using results of experiments, containing air temperatures and air humidity profiles in the canopy, for different values of $x$. The generalised graph presented in Fig. 5 was designed using those results. On axis of ordinates there are values $q(x)-q_{0}$, and on axis of abscissas $\mathrm{Bu}\left(\theta(x)-\theta_{0}\right)$ values, where $\mathrm{Bu}=$ $=\mathrm{d} q / \mathrm{d} \theta=L E(x) /(R(x)-B)$. To design a chart, 
a)

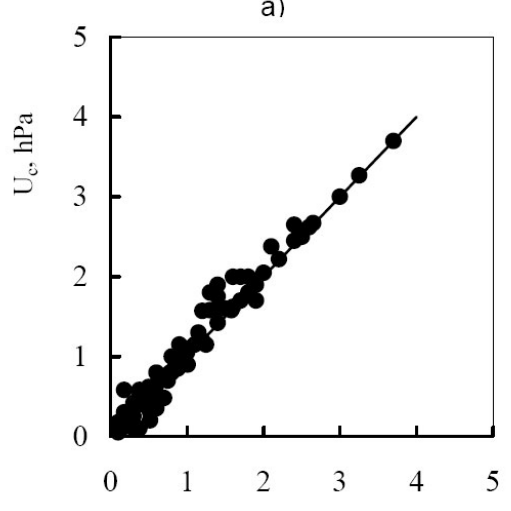

c)

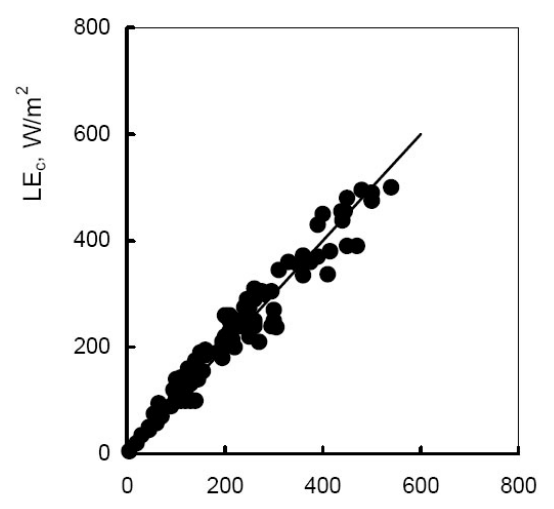

b)

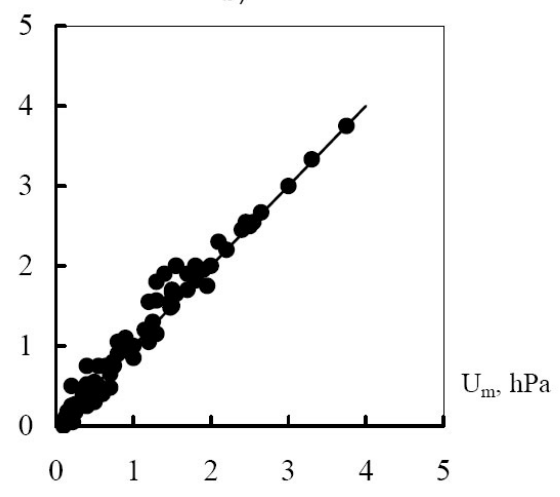

d)

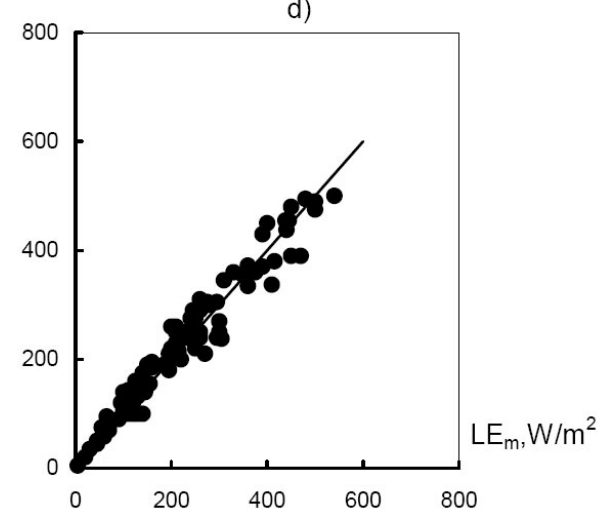

Fig. 4. Comparison of the calculated and the measured values of $U(x)-(a, b)$, and $L E(x)-(c, d)-$ Eqs. (41) and (42). Figs. a) and c) were calculated using individual values of $m_{k}$ and $m_{t}$, b) and d) were calculated with the "average" values of $m_{k}$ and $m_{t}$. Substripts $c$ and $m$ mean calculated and measured values.

the numerous results of measurements were used, acquired by measurements on canopies of maize, wheat and cotton in Estonia, Moldova, Tadjikistan and Russia (Kursk Experimental Station). Mean quadratic errors are shown, not higher than measurement errors of $q(x)$ and $T(x)$, and $\theta(x)$ values as well, while mean quadratic errors are not larger than those above the canopy. Linearity of the relationship discussed means constancy of the $B u$ with height of the plant canopy. Some differences were found in the layer close to the soil surface, which can be characterised by the air layer roughness, close to the bare soil surface.

Using this approach and after transformation of $q_{l}$ to series, and using first two terms of the series $q\left(z_{2}\right)$ and $T\left(z_{2}\right)$ measured at the standard height $z_{2}=$ $=2 \mathrm{~m}$, because this is the height of standard meteorological observations, in basic Eq. (38), two new terms will appear. Rewriting this equation including the variable $\theta(x)$

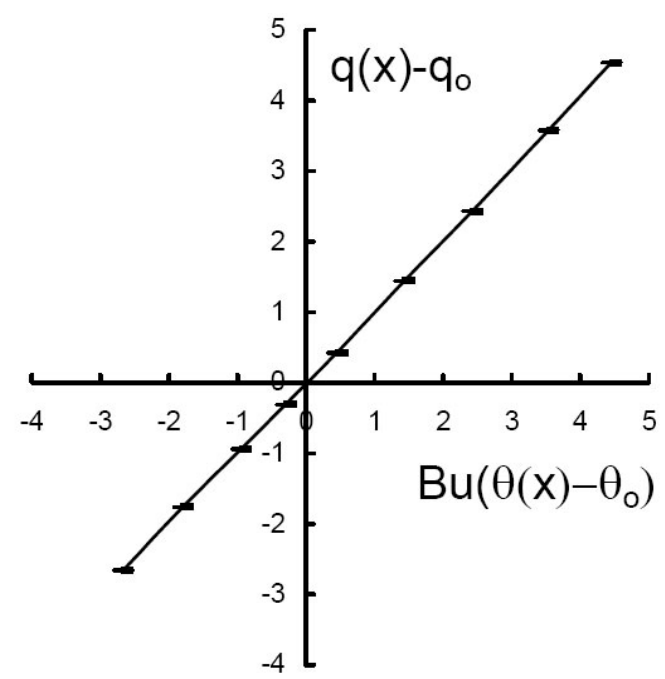

Fig. 5. Relationship between $q(x)-q_{0}$, and $B u\left(\theta(x)-\theta_{0}\right)$. Figure was designed using vertical profiles of $q(x)$ and $\theta(x)$. 


$$
\begin{aligned}
& L E^{\prime}(x)=\frac{1}{1+b_{1} p_{l}}\left[\rho L b_{1} \omega_{0} D_{t}(x) d-\rho L \omega_{0} D_{t}(x)\left(q(x)-q_{0}\right)+\rho L \omega_{0} b_{2}\left(\theta(x)-\theta_{0}\right)-\rho L \omega_{0} D_{t}(x)\left(q_{1}-q_{2}\right)-\right. \\
& \left.-\rho L \omega_{0} D_{t}(x) b_{2}\left(\theta_{1}-\theta_{2}\right)+b_{2} R^{\prime}\right] .
\end{aligned}
$$

Subscripts " 1 " and " 2 " at $q$ and $\theta$ mean, that those are the values for the level of plant canopy, and of the $z_{2}$ height, respectively.

To separate terms $q_{1}-q_{2}$ and $\theta_{1}-\theta_{2}$ from Eq. (43), the following equations are used:

$L E=\rho L D_{0}\left(q_{1}-q_{2}\right)$,

$\left(R_{0}-B\right)=\rho L D_{0}\left(\theta_{1}-\theta_{2}\right)$,

where $D_{0}$ - integral coefficient of turbulent conductivity of the air, between levels $z_{1}$ (plant canopy surface) and $z_{2}$.

Eqs. (34) and (35), will be used, to separate term containing $\theta(x)-\theta_{0}$, to join the energy balance equation, which leads to the relationship

$$
R(x)-B=\frac{\rho L k(x)}{h} \frac{\mathrm{d} \theta}{\mathrm{d} x} .
$$

Integrating this equation according to $x$, from $x$ $=1$ to $x$, and multiplying both parts of this equation by $\omega_{0}$, we can take

$$
\rho L \omega_{0}\left(\theta(x)-\theta_{0}\right)=\frac{\omega_{0} k_{0}}{h} \int_{1}^{x} \frac{R(x)-B}{k^{*}(x)} .
$$

To eliminate the difference $q(x)-q_{0}$, the above mentioned linear relationship between $q(x)$ and $\theta(x)$ can be used. Then, the following equation can be developed

$\frac{q(x)-q_{0}}{\theta(x)-\theta_{0}}=\frac{L E^{\prime}}{R^{\prime}}=\frac{L E(x)}{R(x)-B}=\frac{L E_{0}}{R_{0}-B}$.

To apply the approach presented, for development of the differential equation describing the transpiration process, in principle, any of the three possibilities of the right side of the Eq. (48) can be used. Nevertheless, the final form of this equation depends upon this choice.

The simplest and the most comfortable solution can be obtained, by using the term

$\left(q(x)-q_{0}\right) /\left(\theta(x)-\theta_{0}\right)=L E_{0} /\left(R_{0}-B\right)$.

According to the above mentioned, the expression (43) can be rewritten as follows:

$$
\begin{aligned}
& L E^{\prime}=\frac{1}{1+b_{1} p_{l}}\left\{\rho L \omega_{0} b_{1} D_{\mathrm{t} 0}(x) d-L E_{0} \frac{D_{t 0} h \omega_{0} \mathrm{e}^{m_{t} \omega_{0}(x-1)} \int_{\int}^{x} \frac{(R(x)-B)}{k^{*}(x)} d x}{k_{0}\left(R_{0}-B\right)}-\right. \\
& \left.-\frac{D_{t 0} \mathrm{e}^{m_{\mathrm{t}} \omega_{0}(x-1)} L E_{0}}{D_{0}}+b_{2}\left[R^{\prime}+\frac{D_{t 0}\left(R_{0}-B\right)}{D_{0}}+\frac{D_{t 0} h \omega_{0} \mathrm{e}^{m_{t} \omega_{0}(x-1)}}{k_{0}} \int_{1}^{x} \frac{(R(x)-B)}{k^{*}(x)}\right]\right\}
\end{aligned}
$$

Eq. (49) is a simple differential equation, which can be solved by integration only. It will be done for boundaries from " 1 " (plant canopy surface) to " 0 " (soil surface), without consideration of the thin air layer adjacent to soil surface. It was estimated, as a result of numerous measurements discussed before. But how to apply this knowledge it is not known so far. It can be stated and accepted, that the equations describing the relationships $k(x)$ and $D_{t}(x)$ are valid up to $x=0$. Accepting this assumption, and multiplying both sides of the Eq. (49) by -1 , it is obtained:

$$
\begin{aligned}
& L E_{t p}=\frac{1}{1+b_{1} p_{l}}\left[\rho L b_{1} D_{t 0} d y_{1}-L E_{\mathrm{S}}\left(y_{1}+y_{3}\right)+\right. \\
& +(R-B)\left(y_{2}+A_{1} y_{1}+A_{2} y_{3}\right)-L E_{t p}\left(A_{1} y_{1}+A_{2} y_{3}\right)- \\
& \left.-\delta B A_{2}\left(y_{3}-y_{4}\right)\right]
\end{aligned}
$$

$$
\begin{aligned}
& A_{1}=D_{t 0} / D_{0} ; \quad A_{2}=h D_{t 0} / k_{0} \\
& y_{1}=\left(1-\mathrm{e}^{-m_{t} \omega_{0}}\right) / m_{t} ; \quad y_{2}=1-\mathrm{e}^{-n \omega_{0}}
\end{aligned}
$$




$$
\begin{aligned}
& y_{3}=\frac{1-\mathrm{e}^{-\left(m_{t}+n-m_{k}\right) \omega_{0}}}{\left(m_{k}-n\right)\left(m_{t}+n-m_{k}\right) \omega_{0}}-\frac{1-\mathrm{e}^{-m_{t} \omega_{0}}}{\left(m_{k}-n\right) m_{t} \omega_{0}}, \\
& y_{4}=-\left[\frac{\mathrm{e}^{\left(m_{t}-m_{k}\right) \omega_{0}}-1}{m_{k}\left(m_{t}-m_{k}\right) \omega_{0}}+\frac{\mathrm{e}^{-m_{t} \omega_{0}}-1}{m_{k} m_{t} \omega_{0}}\right] .
\end{aligned}
$$

For the above mentioned rearrangements, the validity of the equation $L E_{p}=L E_{s}+L E_{t p}$ is accepted. Here $E_{\mathrm{s}}$ - soil evaporation rate below canopy, in principle it can influence transpiration rate. For potential rate of $E_{\mathrm{s}}$, air humidity in plant canopy is slightly increasing and its temperature is decreasing. This leads to corresponding transpiration decrease. For $E_{\mathrm{s}} \rightarrow 0$ the turbulent heat transport is increasing too, which leads to air temperature increase, and correspondingly, to increase of the transpiration rate.

There are basic ideas describing the influence of $E_{\mathrm{s}}$ on transpiration rate. Quantitative description of this phenomenon was probably given for the first time by Budagovskij (1964). Quantitative evaluation of this phenomenon indicates, that the influence of $E_{s}$ on transpiration rate can be neglected in practice, for a detailed analysis of the transpiration process. Keeping this in mind, terms containing $E_{s}$ will be neglected in further rearrangements of the Eq. (50).

The last term of the Eq. (50) can be neglected too. It appeared, because integrals containing $R(x)$ and $B$, will be expressed by a single term. Therefore, the last term can be neglected as negligibly small.

It should be noted, that heat fluxes should be involved in the calculation, when studying daily courses of transpiration fluxes only. The differences between daily totals of heat fluxes in soil, usually falls within errors of its estimation.

Coming back to the solution of Eq. (50), the term $L E_{t p}$, will be transferred from the right to the left side of it. After some simple rearrangements, the term of the right side of the equation $1 /\left(1+b_{1} p_{l}\right)$ can be expressed as

$\Phi_{0}=1 /\left(1+b_{1} p_{l}+A_{1} y_{1}+A_{2} y_{3}\right)$.

The right side of the Eq. (51) will be divided by the expression $1 /\left(1+b_{1} p_{10}+A_{1} y_{1}+A_{2} y_{3}\right)$, which corresponds to the optimal soil water content for transpiration. Resulting equation is

$\Phi_{0}=\frac{1+b_{1} p_{l 0}+A_{1} y_{1}+A_{2} y_{3}}{1+b_{1} p_{l}+A_{1} y_{1}+A_{2} y_{3}}$.
To simplify the expression, numerator and denominator of this equation have to be divided by $M=1+A_{1} y_{1}+A_{2} y_{3}$. It can be written then

$\Phi_{0}=\frac{1+b_{1} p_{l 0}{ }^{*}}{1+b_{1} p_{l}^{*}} ; \quad p_{l 0}^{*}=p_{l 0} / M ; \quad p_{l}^{*}=p_{l} / M$

It seems to be suitable to introduce into denominator of the Eq. (52') such a term $b_{1} p_{l}{ }^{*}$, which equals to the value of this term for particular canopy, under condition of optimally hydrated soil. Then, the value of $\Phi_{0}$ will represent the ratio of the given canopy transpiration, and transpiration of the canopy chosen as typical. Let it be expressed as $\Phi_{01}$. In this way, the differences in different kinds of plant canopies transpiration can be evaluated.

The influence of stomata conductivity coefficient - and $\Phi_{0}$ - on transpiration is decreasing before the end of vegetation period. To describe the transpiration process of this period, it is suitable to introduce coefficient $\Phi_{02}(t)$. Its value can be estimated by transpiration of the plant canopy measurements only. To evaluate material of the measurements, it is suitable to use dimensionless time $\tau=\left(t-t_{i}\right) /\left(t_{k}-t_{i}\right)$, where $t$ - time, $t_{i}$ - initial time, and $t_{k}$ - final time of the constant transpiration rate period.

At the end, the coefficient $\Phi_{03}$ should be involved, characterising transpiration at sub-optimal soil water content. The way of its estimation, will be described later.

Now, the part of the Eq. (50) will be analysed. First, the term at the expression $(R-B)$, will be noted as $\Phi_{2}$.

$$
\Phi_{2}\left(\omega_{0}\right)=y_{2}+A_{1} y_{1}+A_{2} y_{3} \text {. }
$$

The second function $-\Phi_{1}$ is much more complicated, because it depends not on $\omega_{0}$ only, but also upon linear leaf dimension in the wind direction $l$. Therefore, $\Phi_{1}$ can be expressed as

$\Phi_{1}=C_{p} \cdot l^{0.5} y_{1}$,

where $C_{p}$ - proportionality coefficient in the relationship $D_{t}=C_{p}(u / l)^{0.5}$. It can be mentioned, that $u$ is not involved in $\Phi_{1}$, but it is in equation with superscript not 0.5 , but $2 / 3$. Correspondingly, the wind velocity in this solution is not given for canopy surface, but for the standard $z_{2}=2 \mathrm{~m}$. 
Taking into consideration the above mentioned comment, the Eq. (50) can be expressed in the form

$$
L E_{t p}=\Phi_{0}\left[\rho L b_{1} u^{2 / 3} d \Phi_{1}+b_{2}\left(R_{0}-B\right) \Phi_{2}\right] .
$$

The Eq. (55) is suitable for evaluation of $\Phi_{1}$ and $\Phi_{2}$ functions, having results of measurements $L E_{t p}$, and $R_{0}, B, d, u_{2}$. To be able to do that, it seems to be reasonable to divide the equation by $\rho L b_{1} d u^{2 / 3}$. Resulting is the simple equation

$$
\begin{aligned}
& Y=\Phi_{1}+\Phi_{2} \bar{X} \\
& Y=L E_{t p} \rho L b_{1} u_{2}^{2 / 3} d ; \quad X=\frac{b_{2}\left(R_{0}-B\right)}{\rho L b_{1} u_{2}^{2 / 3} d} .
\end{aligned}
$$

Data, used to estimate functions $\Phi_{1}$ and $\Phi_{2}$, should fulfil at least the following criteria: the first is - measurements should be conducted above the dense canopy $\left(\omega_{0} \geq 4\right)$, to neglect the soil evaporation. The second condition which should be met is - the canopy should be hydrated optimally and its growth should be optimal too. In other case, results of the measurement will be nonhomogeneous, and values of the functions $\Phi_{1}$ and $\Phi_{2}$ will be inaccurate and incorrect.

Table of $\Phi_{1}, \Phi_{2}$ and functions value was calculated using results of our measurements, as well as materials of other research institutes. Types of canopies are arranged according to their values of function $\Phi_{1}$, starting with their lowest one.

T a b 1 e 3 . Functions $\Phi_{1}, \Phi_{2}$ and $\Phi_{0}$ values, estimated from experimental data.

\begin{tabular}{lccl}
\hline Vegetation type & $\Phi_{1}$ & $\Phi_{2}$ & $\Phi_{0}$ \\
\hline Beets & 0.15 & 1.16 & 0.98 \\
Cotton & 0.20 & 1.21 & 1.00 \\
Corn & 0.20 & 1.18 & 0.98 \\
Alpine meadows & 0.30 & 0.96 & 0.80 \\
Birch-aspen forest & 0.30 & 1.24 & 1.03 \\
Alfalfa & 0.40 & 1.17 & 1.00 \\
Camel thorn & 0.40 & 1.21 & 1.00 \\
Oats & 0.40 & 1.19 & 0.99 \\
Wheat & 0.45 & 1.22 & 1.02 \\
Barley & 0.45 & 1.20 & 0.99 \\
Rice & 0.45 & 1.22 & 1.02 \\
Pine-tree planting & 0.75 & 1.10 & 0.91 \\
\hline
\end{tabular}

It can be mentioned, that in 10 of 12 cases, values of the function $\Phi_{2}$ are very close. Their maximum deviations from the mean value $\bar{\Phi}_{2} \equiv 1.2$ are not higher than $\pm 3 \%$, what is within the interval of systematic errors due to the measuring equipment quality, skill of the personnel, and homogeneity of the experimental field. Therefore, the value $\Phi_{2}=1.2$ can be taken as typical, up to the time, when more experimental material will be collected.

Remembering, that function $\Phi_{0}$ is ratio of the actual transpiration and the potential one, the first value was estimated by dense canopy transpiration measurements, the second one was evaluated using Eq. (55).

The strong influence of the effective leaf diameter $l_{1}$ on function $\Phi_{1}$ can be found easily from Tab. 3 . It can be recalled, that independent measurements of the $l_{1}$ is impossible in principle. Therefore, for $L E$ calculation it is necessary to utilise $\Phi_{1}$ classification, evaluated by the above mentioned method, using the measurement data. This fact cannot be the necessary limitation of the method presented, because the term in the Eq. (55) containing the function $\Phi_{1}$, is not higher - even under extraordinary conditions - then $15-20 \%$ of $L E_{t p}$. The last term was evaluated using $\Phi_{0}=1, \Phi_{0}$ was evaluated by the method described before, results of which are presented in Tab. 3. Values $\Phi_{0}$ in Tab. 3 can be taken - according to the above discussed method - as values $\Phi_{01}$.

From the Tab. 3 it follows, that values of $\Phi_{01}$ for the 10 analysed plant canopies are close too. Minor differences in function values are within the range of evapotranspiration estimation systematic errors.

Analysing the Tab. 3, another important conclusion can be made. It can be concluded, that at the "typical" cases $\Phi_{2}$ and the $b_{1} p_{l 0}^{*}$ does not depend upon $\Phi_{1}$, but on the effective leaf dimension $-l_{l}$.

It was shown in the previous part based on results of laboratory measurements, that the above mentioned term does not depend on wind velocity. Now, this conclusion can be expressed in more general form. It means practically constancy of the ratio $p_{10}=D_{t 0} / D_{10}$, for any type of plant. It can change for different plant types. It is not clear so far, what is role of the air temperature in this term. This problem is discussed in detail by Budagovskij (1989), therefore our presentation here will be limited to his results.

Those conclusions were based on the analysis of results of four years of field measurements with the cotton canopy, in Central Asia. The air temperature during the field measurements changed within the range from 38 to $17^{\circ} \mathrm{C}$, and function $b_{1}$ 
changed from 0.15 to 0.30 , correspondingly, i.e. twofold. Analysis of measurement results has shown, that the differences of evaluated function $\Phi_{2}$ were not higher then $\pm 0.02-0.03$, using values $b_{1}$ from 1.2. Such a differences are within the stochastic errors of transpiration measurements. That means, the independence of the term $b_{1} p_{l 0}^{*}$ does not depend on $b_{1}$ for the particular plant type.

The significant deviation of function $\Phi_{01}$ from the value 1.0 of Alpine meadows and Pine trees will be discussed. Alpine meadows observations were conducted in Armenia, close to Aragac peak at the elevation around $3200 \mathrm{~m}$ a.s.l. Typical for this site is high intensity of the solar radiation, and the low air temperatures. Only those kinds of plants can adapt to those conditions during their evolution - which productivity was the highest. But it basically depends on the leaf temperature, especially at relatively low air temperature. The leaf temperature increase is possible - during the high solar radiation intensity - but it is connected to decrease transpiration intensity. This can occure by partial stomata closing, which leads to limiting $\mathrm{CO}_{2}$ inflow to the substomatal cavities. This is the price for growth under such conditions.

Pine tree behaviour is incomparable to Alpine meadows. Pine trees of different kinds are distributed in wide ranges of altitudes between the subtropic and polar latitudes. The pine leaves, represented by long, thin needles, are covered by the relatively thick cuticle. The relatively high value of heat transport coefficient and relatively thick cuticle is preserving leaf protoplasma to be overheated. Value of the ratio $p_{l 0}=D_{t 0} / D_{l 0}$ is lower than that for other plants, due to the anatomical differences of the pine tree.

Analytical form of function $\Phi_{2}\left(\omega_{0}\right)$ was presented - in brief - before, but to analyse it comfortably, it is written here too

$\Phi_{2}=y_{2}\left(\omega_{0}\right)+A_{1} y_{1}\left(\omega_{0}\right)+A_{2} y_{3}\left(\omega_{0}\right)$,

where $A_{1}=D_{t 0} / D_{0}, A_{2}=D_{t 0} h / k_{0}$. Terms $D_{t 0}, D_{0}$, and $k_{0}$ are correlated and therefore a value of $A_{1}$ and $A_{2}$, are varying in a wide range. Their values can be estimated experimentally. As it was shown, for dense canopy the value of $\Phi_{2}$ is nearly constant and equals to 1.2. The above mentioned equation for $\Phi_{2}\left(\omega_{0}\right)=1.2$ can be used, to estimate $A_{1}$ and $A_{2}$. The Eq. (57) can be expressed in the form

$$
\begin{aligned}
& Y^{*}=A_{1}+A_{2} \bar{X}^{*} \\
& Y^{*}=\left(1.2-y_{2}\right) / y_{1} ; \bar{X}^{*}=\mathrm{y}_{3} / y_{1} .
\end{aligned}
$$

Functions $y_{1}, y_{2}$ and $y_{3}$ are characterized by the above presented relationships, and the parameters $n, m_{t}$ and $m_{k}$ are evaluated independently, using specific field experiments.

Values of the estimated parameters are presented in Tab. 4.

T a b 1 e 4 . Parameters $n, m_{t}$ and $m_{t}$ values.

\begin{tabular}{llll}
\hline & $n$ & $m_{t}$ & $m_{k}$ \\
\hline Number of measurements & 90 & 19 & 16 \\
Mean value & 0.31 & 0.40 & 0.52 \\
Mean quadratic deviation & 0.11 & 0.18 & 0.07 \\
Coefficient of variation [\%] & 35 & 45 & 13 \\
\hline
\end{tabular}

Dispersion of all parameters in the Tab. 4 is significant. Dispersion of parameter $n$ is maximal, particularly because the influence of Sun elevation on its value was neglected. This problem - which seems not to be very important - was discussed in details by Budagovskij (1981). Probably the most important is to establish the correlation between different parameters. To find out those interrelations among parameters is extremely difficult, because parameters are evaluated for different time intervals, due to technical reasons. Mutual measurements of characteristics family is needed to establish interrelations among them.

The most probable values of parameters should be used for evaluation of $A_{1}$ and $A_{2}$ using the Eq. (57). Parameters, presented in Tab. 4 were not evaluated under the same conditions, therefore the average values of them should be used. As it was shown, values $A_{1}=0.1$ and $A_{2}=0.15$, are close to the mean values, but calculation of $\Phi_{2}$ has shown, that results were not of acceptable values.

To increase the accuracy of relationships $\Phi_{2}=$ $=\Phi_{2}\left(\omega_{0}\right)$ estimate, additional field measurements are needed, in which synchronised evaluation of parameters $n, m_{t}$ and $m_{k}$ would be performed. Experimentally estimated data acquired so far, are not satisfactory to evaluate function $\Phi_{2}\left(\omega_{0}\right)$, by a currently used method. It seems to be reasonable to use other methods, e.g. relationship $E_{t} / E_{t p}=$ $=f\left(\omega_{0}\right)$ seems to be an useful tool for it. For $\omega_{0} \geq 4$ $\Phi_{2}=1.2$, from which it follows that the term $E_{t} / E_{t p}$ in this relationship can be multiplied by 1.2. To do that, the analysis made by Novak (1981) can be used, who used data of different authors. The generalised relationship $E_{t} / E_{t p}=f\left(\omega_{0}\right)$ was expressed 
analytically, using his chart, with multiplying of $E_{t} / E_{t 0}$ by 1.2 . Co-ordinates of points of the relationship $\Phi_{2}=f\left(\omega_{0}\right)$ were evaluated there. Graphical representation of this relationship is on Fig. 6.

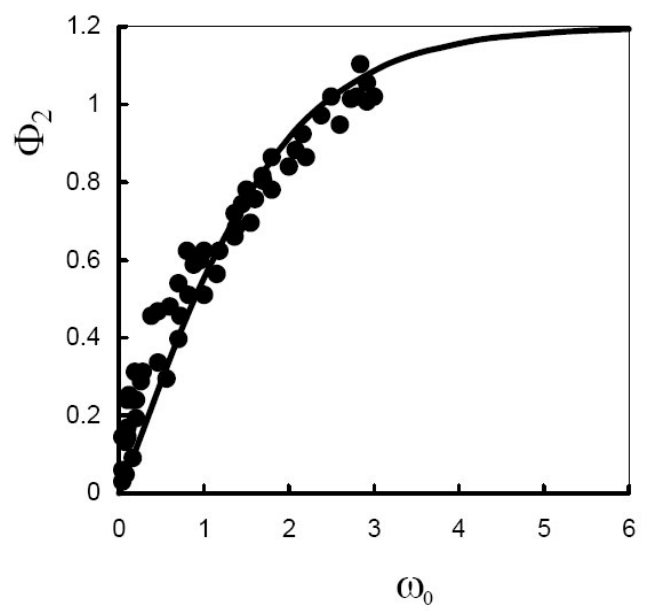

Fig. 6. Function $\Phi_{2}$ and leaf area index $\omega_{0}$. Points were estimated by Novák (1981), the curve was calculated by Eq. (59).

There are some values of function $\Phi_{2}$, in the Tab. 3, which were not used in the figure, because the leaf area index for them was not estimated. According to visual evaluation, leaf area index is changing within the range $4-(6-7)$. From it follows, that within this range of $\omega_{0}$ value, function $\Phi_{2}$ will be nearly constant, with the mean value 1.2 . Using the previously mentioned results, quite simple relationship can be proposed, between $\Phi_{2}$ and the leaf area index

$\Phi_{2}=1.2 \operatorname{th}\left(0.5 \omega_{0}\right)$.

It can be expected, that function $\Phi_{1}\left(\omega_{0}, l_{l}\right)$, for increasing $\omega_{0}$ is converging to the limit, in the same way, as it is with $\Phi_{2}\left(\omega_{0}\right)$. In this case it can be approximated by the same type of expression like that for $\Phi_{2}$. The basic difference is, however, in Eq. (59), where instead of factor 1.2, the function $\Phi_{1}^{*}$ should be applied, in analogy to those, introduced in Tab. 3, or the proposal described above should be used,

$\Phi_{1}\left(\omega_{0}, l_{l}\right)=\Phi_{1}^{*} \operatorname{th}\left(0.5 \omega_{0}\right)$.

As a result, the relationship $\Phi_{1}\left(\omega_{0}\right)$ will be presented by the family of curves, any of them for particular value of the effective leaf dimension. Those should not be - as it was accented before estimated independently. Therefore, there is not alternative way of its estimation, instead of using the Eq. (60). It can be noted, that some differences in evaluation of $\Phi_{1}$, using different mentioned approaches, are not critical for transpiration calculation.

Function $\Phi_{01}$ can be estimated experimentally in the same way, as it was shown before. Classification of this function in relation to its sensitivity to environment would be made, or if necessary, experimental data should be collected.

Parameter $\Phi_{02}=\Phi_{01}$, depends on plant type only for the optimum soil water content. Its value is decreasing at the plant maturity stage. This period for cereals starts just before stage of the wax maturity up to full maturity of the grains. During this stage the lowest leaves are becoming yellow and partially falling down as a result of plastic stuff extraction from them, and its transport into reproductive organs, probably due to decreasing of the $D_{y}$ coefficient. The reason of it is probably biological.

Evaluation of function $\Phi_{02}$ can be made by using the measured values of $E_{t}$ and the calculated ones $E_{t p}$, for given type of plant. The soil water content must be optimal during the measurements. Changing soil water content, as well as the soil water potential during measurements, would lead to data which reflect the influence by those changes. Data, suitable for estimate of $\Phi_{02}$ are not available at that time, therefore we can discuss the problem qualitatively. It should be noted, that the time interval of transpiration during this phase is relatively short.

To evaluate the $\Phi_{03}$ function, first of all the Eq. (6) in dimensionless form will be used. To simplify the final form of the equation, leaf water potential $\psi_{l}$, introduced by the difference $\psi_{k t}-\psi_{k r}$, can be expressed by $\psi_{z}-\psi_{k r}$, where $\psi_{z}$ is the leaf water potential, corresponding to the wilting point. Term $E_{t}=\Phi_{03} E_{t p}$ will be used, to rewrite Eq. (6) in the form

$$
\begin{aligned}
& \frac{d \psi_{l}^{*}}{d t}+K_{p} \beta_{p} \psi_{l}(t)-K_{p} \beta_{p} \psi_{l}(0)- \\
& -\frac{\beta}{\left(\psi_{z}-\psi_{k r}\right) \Phi_{03} E_{t p}}=0, \\
& \text { where } \psi_{l}^{*}=\left(\psi_{l}-\psi_{k t}\right) /\left(\psi_{z}-\psi_{k r}\right) .
\end{aligned}
$$

To solve this problem, a simplified form of the Eq. (21) will be introduced, which can be - using some simplifications - written as 
$\Phi_{03}(t)=1-\psi_{l}^{*}(t)$

where $\psi_{l}^{*}(t)$ is of the same meaning as it is in Eq. (61).

Differentiating (62) according to time, and expressing $\frac{\mathrm{d} \psi_{l}^{*}}{\mathrm{~d} t}$ from (61), the differential equation for $\Phi_{03}$ can be developed as

$$
\begin{aligned}
& \frac{\mathrm{d} \Phi_{03}}{\mathrm{~d} t}+M_{t}(t) \Phi_{03}(t)-K_{p} \beta_{p} \Phi_{03}(0)=0 \\
& M_{t}(t)=\frac{\beta_{p}}{\psi_{\mathrm{z}}-\psi_{k r}} E_{t p}(t)-K_{p} \beta_{p} .
\end{aligned}
$$

Solution of the Eq. (63) can be expressed as

$\Phi_{03}(t)=\mathrm{e}^{-\int^{t} M_{t}(t) \mathrm{dt}}\left[-\Phi_{03}(0)+K_{p} \beta_{p} \Phi_{0} \int_{0}^{t} \mathrm{e}^{M_{t}(t) \mathrm{d} t}\right]$

Form of the Eq. (64) is complex, not very suitable for an analysis. Therefore, numerical experiment was performed, result of which is shown in Fig. 7. Time $t$ is there expressed in the solar time. Numbers at particular curves correspond to the initial dimensionless leaf water potential. Recalling the last one correspond to soil root zone water potential, typical by its slow change in time, in comparison to its significant daily changes. Therefore, these daily changes of soil root zone water potential should be neglected in this analysis.

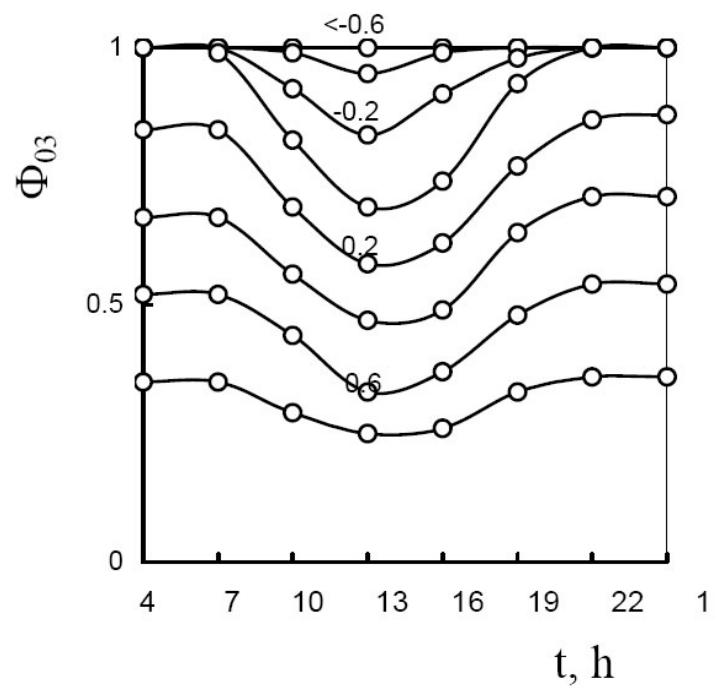

Fig.7. Daily course of functions $\Phi_{03}$ for its different initial values.
Typical daily course of the relationship $\Phi_{03}(t)$ is shown. Daily minimum of this term appears just after noon, when $\psi_{l}^{*}(t)$ reaches its maximum under stable weather condition. It can be noted, that by biophysiologists it was found the mid-day transpiration depression due to non-specified biological properties of plants.

Results of our analysis are demonstrating clearly the noon transpiration depression, which is result of the potential transpiration daily course, and of the term $\psi_{l}^{*}(t)$ initial value.

The relationship $\Phi_{l 0}(t)=f\left(\Phi_{l 0}(0), E_{t p}(t)\right)$ evaluated from data of the numerical experiments should be presented. Difficulties with estimation of the involved parameters are due to lack of systematic observation results of the $K_{p}, \beta_{p}, \psi_{k r}$ and $\psi_{\mathrm{z}}$ coefficients, needed to evaluate the Eq. (64).

It is necessary to use the soil water content instead of the leaf water potential. It can be mentioned, that $\psi_{l}(0)$ equals to the soil water potential, which can be used as proportional to the soil water content, in the range between the wilting point and the field capacity. $\Phi_{03}=E_{t} / E_{t p}$ relationship can be used as directly proportional to the soil water content too, for the constant value of $E_{t p}$. Then, it can be presented

$$
\begin{aligned}
& \Phi_{03}=E_{t} / E_{t p}=\theta / \theta_{k r} \\
& \theta_{k r}(t)=\zeta_{1}+\zeta_{2} E_{t p}(t)
\end{aligned},
$$

where $\zeta_{1}$ and $\zeta_{2}$ are parameters evaluated using directly measured data $W(t), E_{t}(t)$, and meteorological data necessary to calculate $E_{t p}$. Fig. 8 presents the relationship (65). Soil water content $\theta$ is expressed in volumetric units. Potential transpiration is expressed in $\mathrm{mm} \mathrm{h}^{-1}$. Then, there the following values were obtained: $\zeta_{1}=6.0 ; \zeta_{2}=4.6$.

It could be mentioned, that the Eq. (65) is a good approximation of the Eq. (64), and can be used to estimate the influence of the soil water content on transpiration. This can be demonstrated simply. Knowing course of the $E_{t p}(t), \theta_{k r}$ can be calculated according to formula (65), for maximum value of the $E_{t p}$. Different values of $\theta / \theta_{k r} \approx$ $\Phi_{03}$, are shown on horizontal axis, on vertical axis there are the $E_{t p}=f(t)$ values.

Then, values of $\Phi_{03}=f\left(E_{t p}\right)$, can be calculated according to formula (65), for any chosen initial value of the $\theta / \theta_{k r}$. Results of those estimations are giving the picture close to those, as in Fig. 7, closely approximating the numerical experiment. 
It means that this approximation is acceptable and additionally, a simple one.

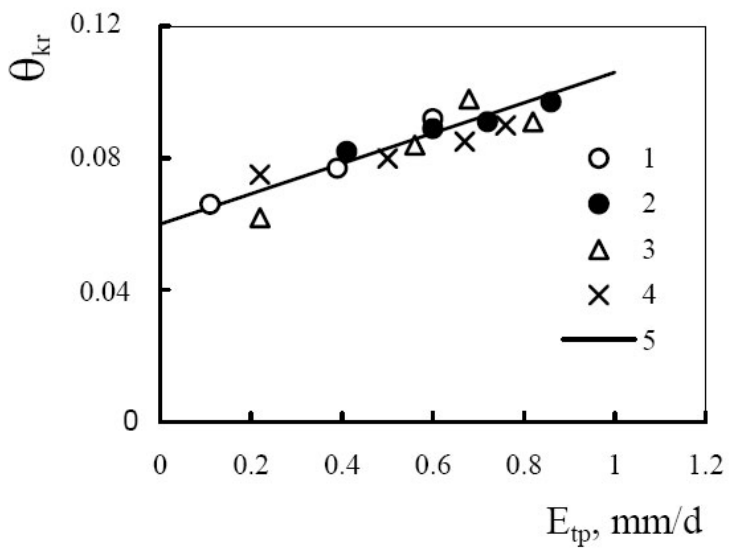

Fig. 8. Critical soil water content $\theta_{k r}$ versus potential transpiration $E_{t p} ; 1$ - barley, 2 - pearl millet, 3 - polygonum sativa, 4 - maize. Linear approximation (5) is according to the Eq. (65).

Third stage of the transpiration starts at $\psi_{l}^{*}>1$ and at $\Phi_{03} \leq 0.2$, respectively. This stage, in fact practically is not covered by the field experiments.

Referring to this, we will limit our discussion to a qualitative level. Cultural plants - under condition of the third stage of transpiration - usually die away, or their ontogenesis is not leading to the production of economically valuable part of plant (grain, fruit). The third stage of transpiration during the later stages of ontogenesis (milk ripeness, etc.), usually ends in basic decrease of the yield and biomass production. Xerophytes and xeromorphous plants are adapted to withstand drought. As it was shown by Maximov (1950) - one of the leading plant physiologist - xerophytes under conditions of optimal soil water content are transpiring at the same rate like mezophytes - plants grown usually in conditions with optimum or slightly decreased soil water content.

At the end of this part, an important interval $0<$ $<\psi_{l}^{*}<1$ should be mentioned here. In it, the relative transpiration is decreasing slower, than the biomass production intensity (Budagovskij, Golubas, 1994).

Acknowledgement. Author is grateful to the VEGA agency (Projects No. 2/7091/27 and 2/0021/10) for partial support of this work.
List of symbols

$A \quad$ - area, $\left[\mathrm{L}^{-2}\right]$,

$B \quad$ - soil heat flux $\left[\mathrm{L}^{2} \mathrm{M} \mathrm{T}^{-2}\right]$,

$C_{\mathrm{s}}^{*} \quad$ - specific heat capacity of a wet soil $\left[\mathrm{L}^{2} \mathrm{~T}^{-2} \mathrm{~K}^{-1}\right]$,

$C_{w} \quad$ - water specific heat capacity $\left[\mathrm{L}^{2} \mathrm{~T}^{-2} \mathrm{~K}^{-1}\right]$,

$C_{s}$ - specific heat capacity of the solid fraction of soil $\left[\mathrm{L}^{2} \mathrm{~T}^{-2} \mathrm{~K}^{-1}\right]$

$D_{l} \quad$ - water vapour conductivity between leaf and its environment $\left[\mathrm{L} \mathrm{T}^{-1}\right]$,

$D_{t} \quad$ - heat conductivity between leaf and its environment $\left[\mathrm{L} \mathrm{T}^{-1}\right]$,

$D_{y} \quad$ - stomata conductivity $\left[\mathrm{L} \mathrm{T}^{-1}\right]$,

$D_{0} \quad$ - turbulent conductivity of air layer between levels $z_{1}$ (the top of the canopy) and $z_{2}\left[\mathrm{~L} \mathrm{~T}^{-1}\right]$,

$E_{t} \quad-$ transpiration rate $\left[\mathrm{L}^{3} \mathrm{~L}^{-2} \mathrm{~T}^{-1}\right]$,

$E_{t p} \quad$ - potential transpiration rate $\left[\mathrm{L}^{3} \mathrm{~L}^{-2} \mathrm{~T}^{-1}\right]$,

$E$ - evapotranspiration rate $\left[\mathrm{L}^{3} \mathrm{~L}^{-2} \mathrm{~T}^{-1}\right]$,

$E_{l p} \quad$ - leaf transpiration at optimal leaf water content (potential transpiration) $\left[\mathrm{L}^{3} \mathrm{~L}^{-2} \mathrm{~T}^{-1}\right]$

$E_{l} \quad$ - transpiration from the unit of leaf area $\left[\mathrm{L}^{3} \mathrm{~L}^{-2} \mathrm{~T}^{-1}\right]$,

$E_{p} \quad$ - potential evapotranspiration rate $\left[\mathrm{L}^{3} \mathrm{~L}^{-2} \mathrm{~T}^{-1}\right]$,

$E_{s p} \quad$ - potential evaporation rate $\left[\mathrm{L}^{3} \mathrm{~L}^{-2} \mathrm{~T}^{-1}\right]$,

$E_{s} \quad$ - soil evaporation rate $\left[\mathrm{L}^{3} \mathrm{~L}^{-2} \mathrm{~T}^{-1}\right]$,

$H \quad$ - precipitation $\left[\mathrm{L}^{3} \mathrm{~L}^{-2}\right]$,

$I_{a}$ - long-wave radiation of the atmosphere $\left[\mathrm{L}^{2} \mathrm{M} \mathrm{T}^{-2}\right]$,

$I_{e} \quad$ - long-wave radiation balance $\left[\mathrm{L}^{2} \mathrm{M} \mathrm{T}^{-2}\right]$,

$I_{l}$ - long-wave emission of the land surface $\left[\mathrm{L}^{2} \mathrm{M} \mathrm{T}^{-2}\right]$,

$K_{p} \quad$ - integral hydraulic conductivity of a canopy $\left[\mathrm{L}^{3} \mathrm{~L}^{-2} \mathrm{~T}^{-1}\right]$,

$L \quad$ - latent heat of evaporation $\left[\mathrm{L}^{2} \mathrm{~T}^{-2}\right]$,

$P \quad-$ sensible heat flux $\left[\mathrm{L}^{2} \mathrm{M} \mathrm{T}^{-2}\right]$,

$R \quad$ - net radiation $\left[\mathrm{L}^{2} \mathrm{M} \mathrm{T}^{-2}\right]$

$R_{0} \quad$ - net radiation at the top canopy level $\left[\mathrm{L}^{2} \mathrm{M} \mathrm{T}^{-2}\right]$,

$T$ - air temperature $\left[{ }^{\circ} \mathrm{C}\right]$,

$T_{*} \quad$ - scaling parameter for air temperature,

$T_{l} \quad$ - leaf temperature $\left[{ }^{\circ} \mathrm{C}\right]$,

$T_{2}$ - air temperature at height $\mathrm{z}_{2}\left[{ }^{\circ} \mathrm{C}\right]$,

$V \quad$ - volume $\left[\mathrm{L}^{3}\right]$,

$c_{p}$ - specific heat capacity of air at constant pressure $\left[\mathrm{L}^{2} \mathrm{M} \mathrm{T}^{-2} \mathrm{~K}^{-1}\right]$,

$d \quad-$ air humidity deficit [-],

$h \quad$ - hydraulic head [L],

$k \quad-$ coefficient of turbulent transport $\left[\mathrm{M}^{2} \mathrm{~T}^{-1}\right]$,

$l$ - length of an element under study in the direction of wind speed [L],

$q$ - absolute air humidity [-],

$q_{*} \quad$ - scaling parameter for absolute air humidity,

$q^{\prime} \quad$ instantaneous fluctuations of absolute air humidity $[-]$,

$q_{l} \quad$ - saturated absolute air humidity in inter-cells leaf space $[-]$,

$r_{a} \quad-$ canopy aerodynamic resistance $\left[\mathrm{T} \mathrm{L}^{-1}\right]$,

$r_{s} \quad$ - stomata resistance $\left[\mathrm{T} \mathrm{L}^{-1}\right]$,

$v_{l}^{*} \quad-$ dimensionless leaf water content $[-]$,

$v_{l} \quad-$ water content per unit leaf area $\left[\mathrm{L}^{-2}\right]$,

$v_{p}$ - rate of water flow from soil to the plant leaves $\left[\mathrm{L}^{3} \mathrm{~L}^{-2} \mathrm{~T}^{-1}\right]$

$w^{\prime}$ - instantaneous fluctuations of the vertical component of wind speed $\left[\mathrm{L} \mathrm{T}^{-1}\right]$,

$z$ - vertical coordinate [L],

$\alpha$ - albedo [-],

$\varepsilon \quad-$ thermal emisivity [-],

$\rho-$ air density $\left[\mathrm{M} \mathrm{L}^{-3}\right]$, 
Theory of evapotranspiration. 1. Transpiration and its quantitative description

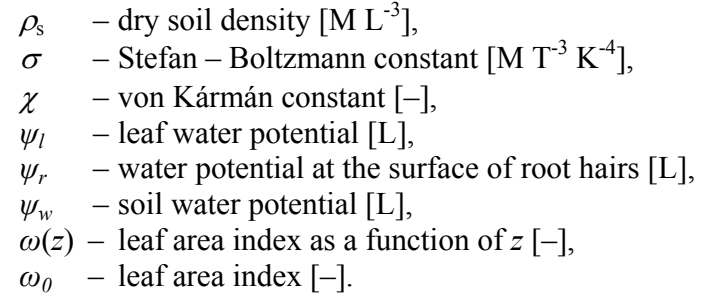

\section{REFERENCES}

BICHELE Z.N., MOLDAU C.A., ROSS J.K., 1980: Mathematical modelling of transpiartion and photosyntesis of plants under soil water limiting conditions. (In Russian.) Leningrad, Gidrometizdat Publ. House, pp. 224.

BUDAGOVSKYI A.I., 1964: Soil water evapotranspiration. (In Russian.) Moscow, Nauka Publ. House, pp. 244.

BUDAGOVSKYI A.I., 1981: Soil water evapotranspiration. (In Russian.) In: Physics of soil water, (Budagovskij, A.I. Ed.), Moscow, Nauka Publ. House, 13-92.

BUDAGOVSKYI A.I., GOLUBAS T.J. 1994: The influence of water in plant production process. (In Russian with English summary.) Vodnyje resursy, 21, 2, 133-143.

BUDAGOVSKYI A.I., 1989: Semiempirical theory of transpiration and plant canopy water regime. (In Russian with English summary.) Vodnyje resursy, 2, 5-17.

BUDAGOVSKYI A.I., LOZINSKAJA E.A., 1996: Heat and water transport in a canopy. (In Russian with English summary.) Vodnyje resursy, 23, 6, 658-667.

BUDAGOVSKYI A.I., LOZINSKAJA E.A., 1998: Semiempirical theory of evapotranspiration. (In Russian with English summary.) Vodnyje resursy, 25, 5, 562-570.

CELICHEVA L.K., 1965: The influence of dry soil layer thickness and free porosity on evaporation. (In Russian with English summary.) Pochvovedenie (Russian Soil Sci.), No. 3 .

DANDARON Ž.D., 1957: The influence of evaporation rate on the dry soil layer thickness. (In Russian.) In: Trudy Burjat-Mongolskovo zoovet. In-ta. Vol.11.

GARDNER W.R., 1957: Some steady-state solutions of the unsaturated moisture flow equation with application to evaporation from a water table. Soil Sci., 85, No. 4.

KURSANOV A.L., 1976: Assimilates transport in plant. (In Russian.) Moscow, Nauka Publ. House, pp. 646.
LOZINSKAJA E.A., 1981: Evaluation of the influence of Magnus formula linearisation on accuracy of evaporation and transpiration calculation from the irrigated soil. (In Russian with English summary.) Vodnyje resursy, 2, $50-55$.

MAXIMOV N.A., 1958: Short course of plant physiology. (In Russian.) Moscow, Selchozgiz Publ. House, pp. 566.

MONIN A.S., 1953: About the mechanics of the air warming in the open steppe landscape. Microclima and clima study at Caspic lowland. (In Russian.) Moscow, Publ. House of the Russian Academy of Sciences, 100-103.

MONIN A.S., OBUCHOV A.M., 1954: Basic rules of turbulent mixing in atmosphere boundary layer. (In Russian.) Proc. Geophys. Inst. Academy of Sciences of the USSR, No. 24 (151), 163-187.

MOROZOV A.T., 1938: Methods of water vapour transport in soils estimation. (In Russian.) Proc. of the Institute of hydrotechnics and amelioration. 22, 211-224.

MUROMCEV I.A., 1969: Active part of plant root system. (In Russian.) Moscow, Kolos Publ. House, pp. 247.

NOVÁK V., 1981: Soil water movement during evapotranspiration. (In Russian.) In: Physics of soil water (Budagovskij A. I., Ed.), Moscow, Nauka Publ. House, 160-181.

PENMAN H.L., 1948: Natural evaporation from open water, bare soil and grass. Proc. Roy. Soc. London, Sect. A, vol. 193, No. 1.

PETERBURSKIJ A.B., 1964: Nutrition of plants by roots. (In Russian.) Moscow, Rosselchozizdat Publ. House, pp. 254.

WAISEL Y., ESHEL A., KAFKAFI U., (Eds.), 1996: Plant roots. The hidden half. 1996. Marcel Dekker, Inc., New York, pp. 1002.

ROSS J.K., 1975: Radiation regimen and architecture of canopies. (In Russian.) Leningrad, Gidrometizdat Publ. House, pp. 342.

SABININ D.A., 1955: Physiological basis of plant nutrition. (In Russian.) Moscow, Publ. House of the Russian Academy of Sciences, pp. 512.

TARCEVSKIJ I.A., ZOLKEVICZ V.I. (Eds.), 1989: Water balance of plants. (In Russian.) Moscow, Nauka Publ. House, pp. 256.

Received 21 May 2010

Accepted 23 June 2010 